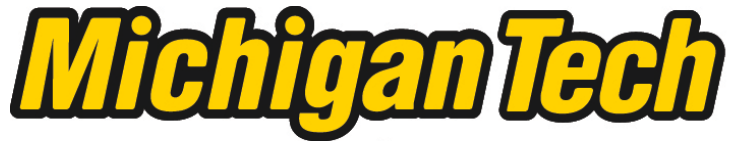 \\ Michigan Technological University Create the Future Digital Commons @ Michigan Tech
}

Dissertations, Master's Theses and Master's Reports - Open

Dissertations, Master's Theses and Master's

Reports

2012

\section{Analysis of a novel waste heat recovery mechanism for an I.C. engine}

Jasdeep S. Condle

Michigan Technological University

Follow this and additional works at: https://digitalcommons.mtu.edu/etds

Part of the Mechanical Engineering Commons

Copyright 2012 Jasdeep S. Condle

\section{Recommended Citation}

Condle, Jasdeep S., "Analysis of a novel waste heat recovery mechanism for an I.C. engine", Master's report, Michigan Technological University, 2012.

https://doi.org/10.37099/mtu.dc.etds/551

Follow this and additional works at: https://digitalcommons.mtu.edu/etds

Part of the Mechanical Engineering Commons 
ANALYSIS OF A NOVEL WASTE HEAT RECOVERY MECHANISM FOR AN I.C.

ENGINE

\author{
By \\ Jasdeep S. Condle
}

\begin{abstract}
A REPORT
SUBMITTED In Partial Fulfillment Of The Requirements For The Degree Of MASTER OF SCIENCE

(Mechanical Engineering)
\end{abstract}

MICHIGAN TECHNOLOGICAL UNIVERSITY

2012

COPYRIGHT @ JASDEEP S. CONDLE 2012 
This report, "Analysis of a Novel Waste Heat Recovery Mechanism for an I.C. Engine," is hereby approved in partial fulfillment of the requirements for the Degree of MASTER OF SCIENCE IN MECHANICAL ENGINEERING.

Department of Mechanical Engineering-Engineering Mechanics

Signatures:

Report Advisor

Scott A. Miers

Department Chair

William W. Predebon

Date 


\section{Table of Contents}

Chapter 1 Introduction................................................................................................................. 11

1.1 Rankine Cycle

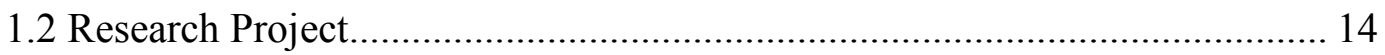

1.2.1 Heat exchanger between the coolant system and the working fluid 15 1.2.2 Heat exchanger between the exhaust system and the working fluid 17 1.2.3 Steam chamber within the modified piston assembly...................... 18

1.2.4 Condenser, pump and piping ……………………….................... 19

Chapter 2 Background/Literature Review ................................................................... 20

Chapter 3 Experimental Setup ........................................................................................ 22

3.1 Modeling of Waukesha 16V275GL+ engine:................................................ 24

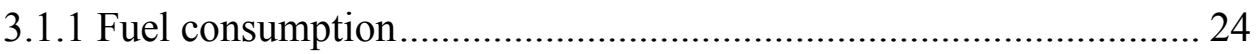

3.1.2 Intake and exhaust valves ........................................................... 24

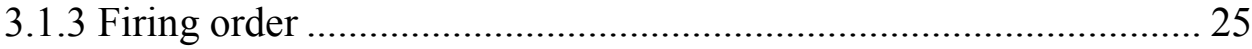

3.1.4 Compressor, turbine and intercooler............................................... 26

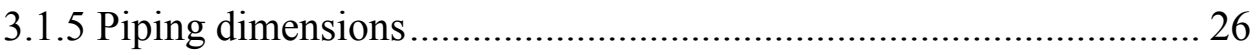

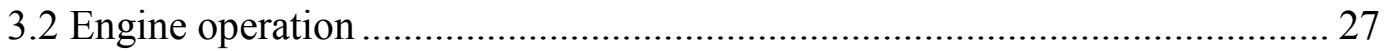

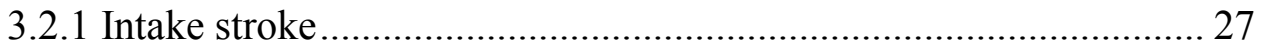

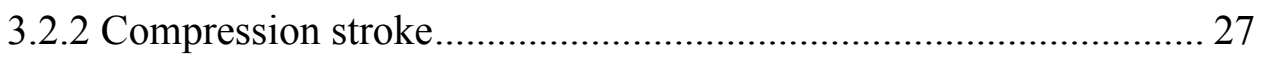

3.2.3 Expansion stroke .............................................................................. 27

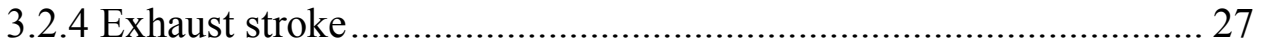

Chapter 4 Results ........................................................................................................................ 29

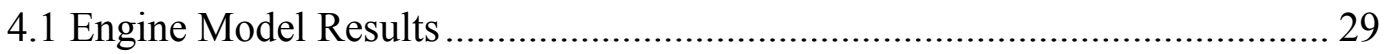

Page 3 of 65 
4.2 Analysis of the Steam Chamber.

4.2.1 Optimization of valve timings ................................................... 35

4.2.2 Inlet steam valve: ........................................................... 35

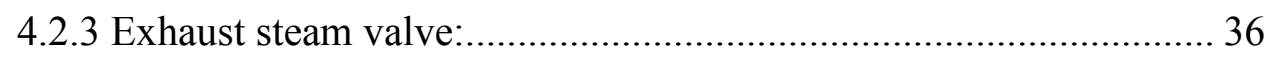

Chapter 5 Conclusions and Future Work ............................................................ 39

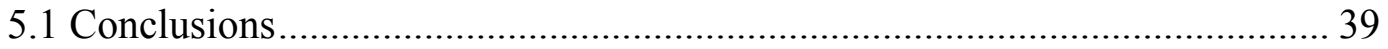

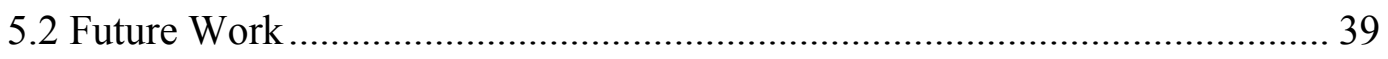

Appendix A..................................................................................................................................... 44

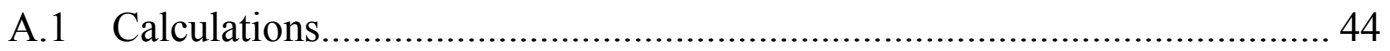

A.1.1 Exhaust gas properties ................................................... 44

A.1.2 Waste heat recovery from the exhaust heat exchanger ............... 44

A.1.3 Energy required to raise the temperature of the working fluid from

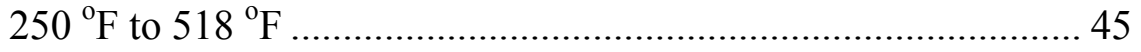

A.1.4 Energy required to evaporate the working fluid at $518^{\circ} \mathrm{F}$ and 800 psia 45

A.1.5 Energy required to raise the temperature of the working fluid from

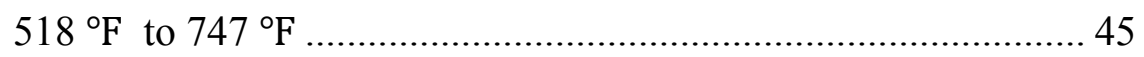

A.1.6 Total energy required to raise the temperature of the working fluid

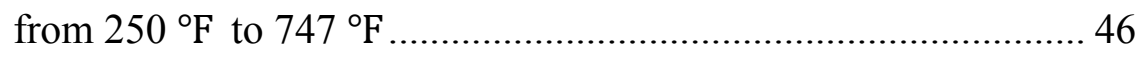

A.1.7 Maximum WHR from coolant heat exchanger.......................... 47

A.1.8 Energy required to raise the temperature of the working fluid from

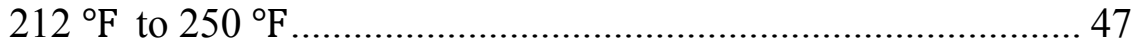

A.1.9 Steam chamber bore size ............................................... 47 
A.1.10 Assuming 2 cylinders are equipped with novel WHR system steam chambers

A.1.11 Assuming 6 cylinders are equipped with DYNAMAX steam chambers 49

A.1.12 Theoretical power generation from WHR 50

A.1.13 Total amount of recovered waste heat 50

A.1.14 Power generation BEFORE any parasitic losses ............................ 50

A.1.15 Estimated parasitic losses ............................................................. 50

A.1.16 Loss from working fluid pump power input .................................. 51

A.1.17 Loss from exhaust heat exchanger backpressure ........................... 52

A.2 DESIGN OF THE HEAT EXCHANGER [4] ......................................... 52

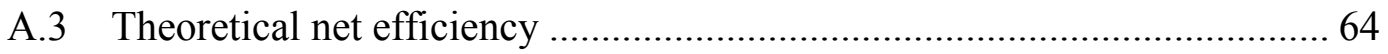

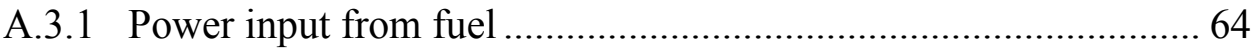

A.3.2 New efficiency of the system......................................................... 64

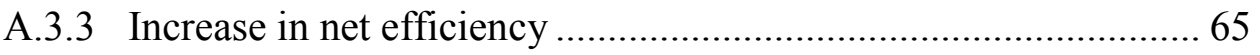




\section{List of Figures}

Figure 1.1: Rankine cycle schematic and its characteristics [6] .................................... 12

Figure 1.2: Efficiencies of different working fluids for various turbine inlet temperatures

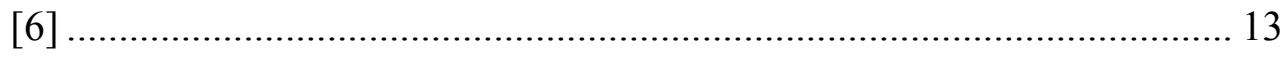

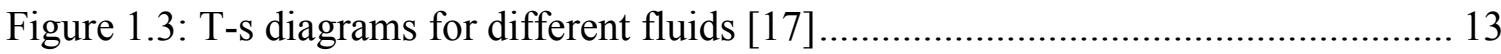

Figure 1.4: Novel waste heat recovery system schematic ............................................... 15

Figure 1.5: Coolant heat exchanger schematic [14]................................................... 16

Figure 1.6: Different types of compact heat exchangers [4].......................................... 17

Figure 3.1:Waukesha 16V275GL+ engine [7]....................................................... 22

Figure 3.2: Sizing of the intake and exhaust valves........................................................... 25

Figure 3.3: Schematic diagram of the modified piston assembly [25] ............................ 28

Figure 4.1: GT-POWER simulation results for brake power (HP)................................. 29

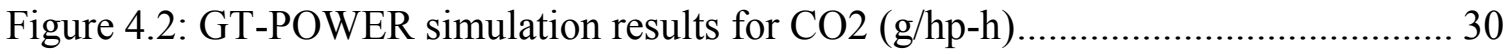

Figure 4.3: GT-POWER simulation results for air flow (scfm) …............................... 30

Figure 4.4: GT-POWER results of exhaust gas flow rate $(\mathrm{kg} / \mathrm{hr})$ for 1 turbocharger ...... 31

Figure 4.5: GT-POWER results of exhaust temperature $\left({ }^{\circ} \mathrm{C}\right)$....................................... 32

Figure 4.6: Pressure cycle with 2 steam power cycles every 2 crankshaft revolutions .... 34

Figure 4.7: $\log \mathrm{P}$ vs. $\log \mathrm{V}$ for the steam chamber.................................................... 35

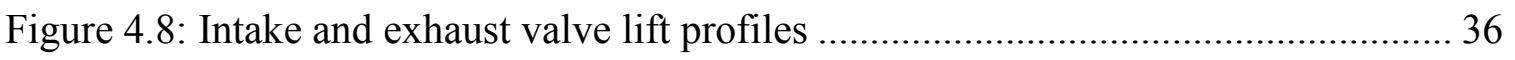

Figure 4.9: Trapped mass inside the steam chamber ........................................................ 37

Figure 4.10: Intake and exhaust lift profiles combined with the trapped mass within the

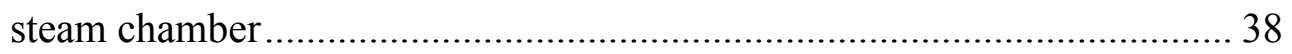

Figure A.1.2: Efficiency of annular fins of rectangular profile [4] ………………….... 58 
Figure A.1.4: Predicted trend of pressure (psia) vs. volume (cu.ft) of the exhaust heat

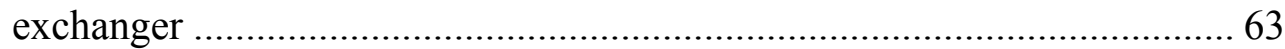

Page 7 of 65 


\section{List of Tables}

Table 3.1: Performance data of the Waukesha 16V275GL+ engine [7] ....................... 23

Table 3.2: Technical data of the Waukesha 16V275GL+ engine [7] ............................ 24

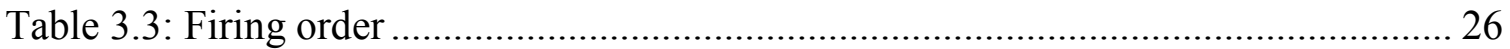

Table 4.1: Error (\%) between the simulated engine model and the actual Waukesha

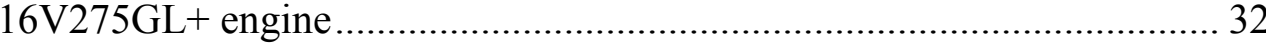

Page 8 of 65 


$\begin{array}{ll}\text { Nomenclature } \\ \text { WHR } & \text { Waste Heat Recovery } \\ \text { ORC } & \text { Organic Rankine Cycle } \\ \text { CAE } & \text { Computer-Aided Engineering } \\ \text { BDC } & \text { Bottom Dead Center } \\ \text { TDC } & \text { Top Dead Center } \\ \text { CAD } & \text { Crank Angle Degrees } \\ \text { k } & \text { Specific heat ratio } \\ \text { Cp } & \text { Specific heat at constant pressure } \\ \text { Cv } & \text { Specific heat at constant volume } \\ \dot{\mathrm{m}} & \text { Mass flow rate } \\ \eta & \text { Efficiency } \\ \rho & \text { Density } \\ \dot{\forall} & \text { Volumetric flow rate }\end{array}$

Page 9 of 65 


\begin{abstract}
Typical internal combustion engines lose about $75 \%$ of the fuel energy through the engine coolant, exhaust and surface radiation [6]. Most of the heat generated comes from converting the chemical energy in the fuel to mechanical energy and in turn thermal energy is produced. In general, the thermal energy is unutilized and thus wasted. This report describes the analysis of a novel waste heat recovery (WHR) system that operates on a Rankine cycle. This novel WHR system consists of a second piston within the existing piston to reduce losses associated with compression and exhaust strokes in a four-cycle engine. The wasted thermal energy recovered from the coolant and exhaust systems generate a high temperature and high pressure working fluid which is used to power the modified piston assembly. Cycle simulation shows that a large, stationary natural gas spark ignition engine produces enough waste heat to operate the novel WHR system. With the use of this system, the stationary gas compression ignition engine running at $900 \mathrm{RPM}$ and full load had a net increase of $177.03 \mathrm{~kW}$ (240.7 HP). This increase in power improved the brake fuel conversion efficiency by $4.53 \%$.
\end{abstract}




\section{Chapter 1 Introduction}

Thermal energy is predominantly released through the coolant and exhaust systems of a typical internal combustion engine. About $20 \%$ of the energy released during combustion power produced by burning fuel is able to be used for work output. The rest of the fuel energy is expelled from the engine as wasted heat [6]. The proposed WHR system makes use of this wasted heat and thus improves fuel conversion efficiency of the internal combustion engine. It makes use of a Rankine cycle to convert the thermal energy into useful work.

Previous work investigated the operation of a DYNAMAX ${ }^{\mathrm{TM}}$ technology on a class 8 diesel engine and showed a similar percentage of large amount of waste heat generated $[1,2]$. The natural gas spark ignition engine used for this project proportionally gives a larger amount of waste heat. The amount of useful work or exergy available is based on the temperature differences between the hot and cold reservoirs $[1,2]$. The following section describes the use of a modified Rankine cycle which recovers the wasted energy from the coolant and exhaust systems to power the modified piston assembly.

\subsection{Rankine Cycle}

The Rankine cycle is a thermodynamic cycle that converts heat into work [6]. The Rankine cycle system consists of a turbine, pump, condenser and boiler. Figure 1.1 shows the ideal Rankine cycle and its characteristics in a temperature-entropy. 

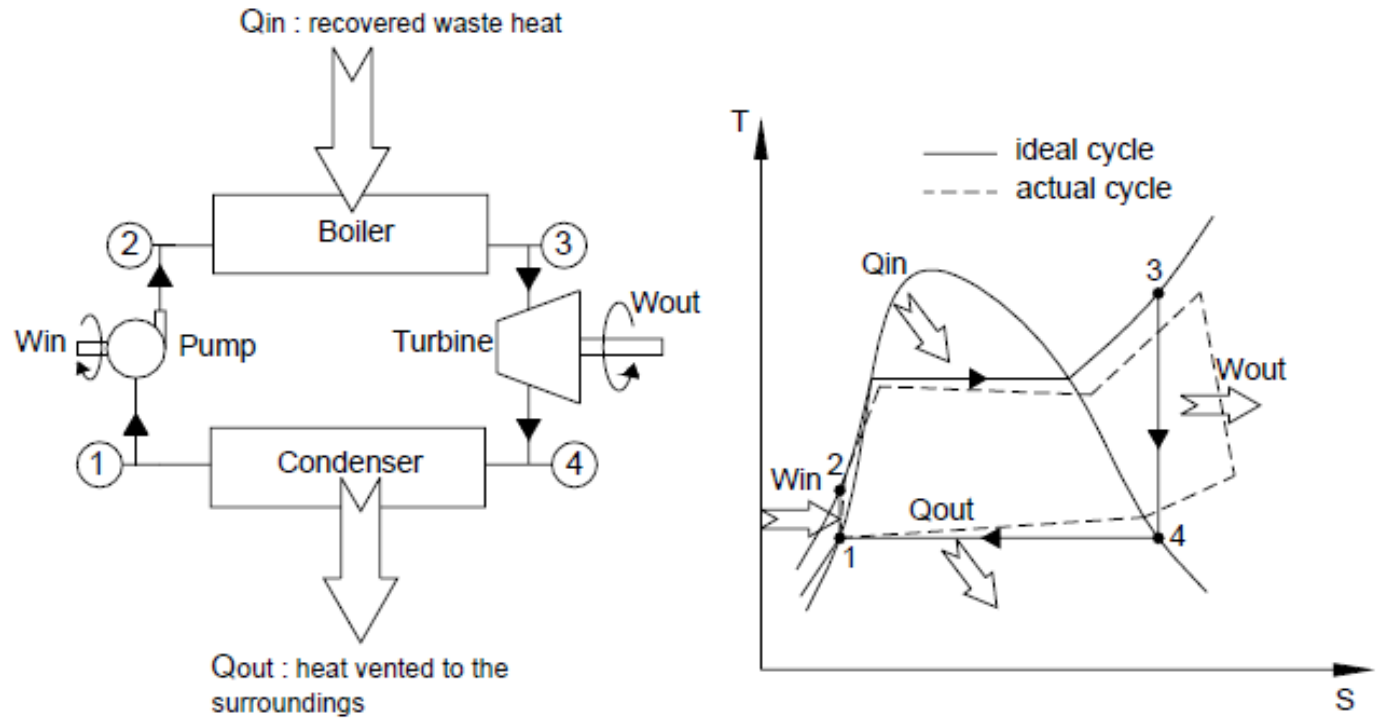

Figure 1.1: Rankine cycle schematic and its characteristics [6]

The ideal Rankine cycle consists of the following four processes:

$1-2$ : compression via pump

$2-3$ : heat delivery at constant pressure in a boiler

3 - 4: isentropic expansion via turbine

$4-1$ : heat rejection at constant pressure in a condenser

The efficiency of the Rankine cycle is limited by the use of the working fluid. In a Rankine cycle system, the working fluid is reused continuously and follows a closed loop. Water is a commonly used working fluid but becomes inefficient for WHR at temperatures below $370^{\circ} \mathrm{C}[9,10]$. For temperatures below $370^{\circ} \mathrm{C}$, the use of organic fluids increases the Rankine cycle efficiency [9, 10, 12]. An Organic Rankine Cycle (ORC) is a Rankine cycle that uses organic fluid. Figure 1.2 shows the efficiencies of different working fluids versus turbine inlet temperatures. Note there can be an issue of formation of liquid droplets on the turbine blades during the expansion process. To eliminate this possibility, an Organic Rankine Cycle (ORC) is used. 


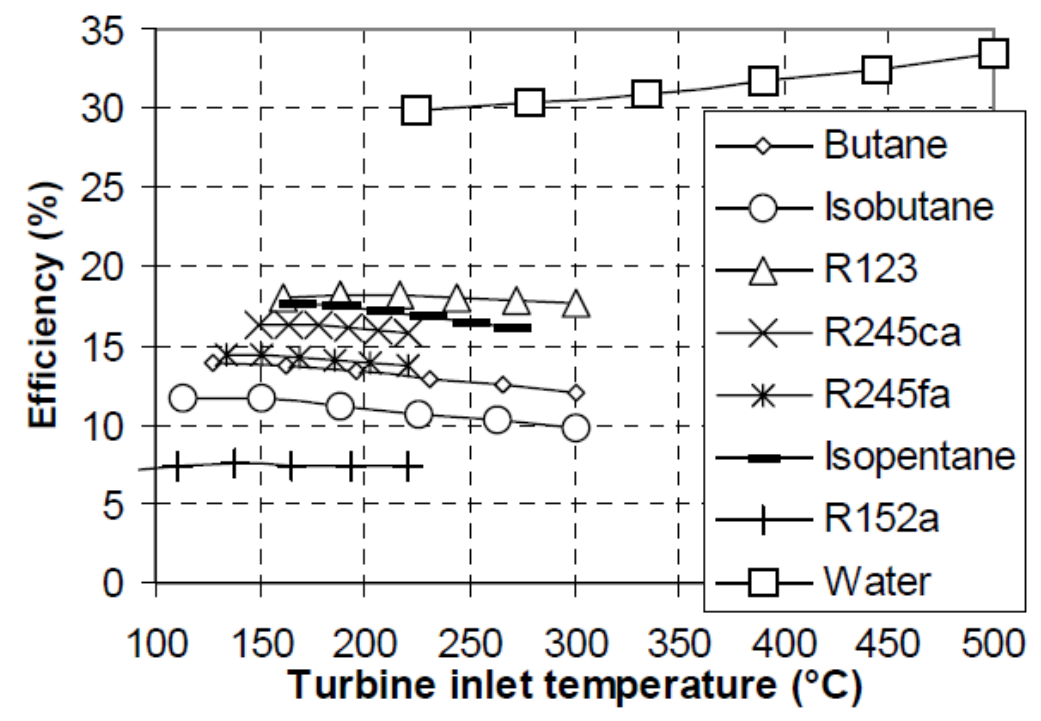

Figure 1.2: Efficiencies of different working fluids for various turbine inlet temperatures [6]
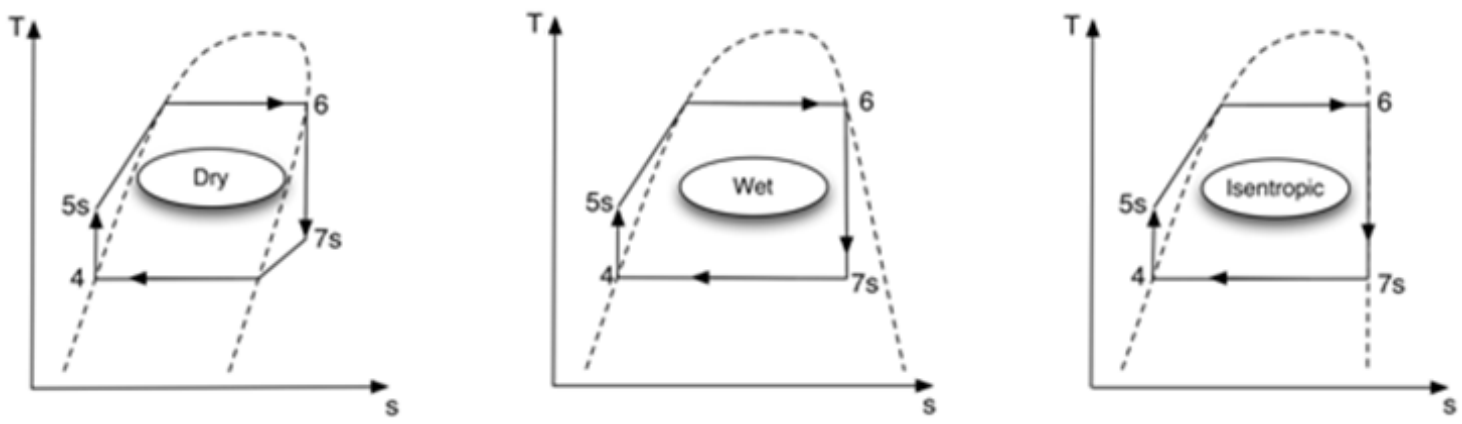

Figure 1.3: T-s diagrams for different fluids [17]

The three types of working fluids are dry, wet and isentropic which are shown in Figure 1.3. The type of working fluid is determined by the slope of the saturated vapor line on the T-s diagram. The slopes of dry, wet and isentropic fluids are positive, negative and infinite respectively. ORC systems use dry or isentropic working fluid because they are superheated after isentropic expansion. This eliminates the need for a superheated apparatus because there is no longer a concern that liquid droplets could form on the turbine blades [10]. The choice of working fluid is discussed in the following section. 


\subsection{Research Project}

A stationary natural gas spark ignition engine was simulated in GT-POWER and a waste heat recovery system was used to evaluate the overall efficiency of the system. The engine simulated in this research was a Waukesha 16V275GL+ stationary natural gas spark ignition engine. The simulation software used in this project was GT-POWER from Gamma Technologies Inc., version 7.1.0.

GT-POWER is a Computer-Aided Engineering (CAE) tool used for the simulation of internal combustion engines. It is an industry standard simulation tool that is widely used by many leading vehicle and engine manufacturers worldwide [13]. The Waukesha 16V275GL+ engine model was optimized in GT-POWER until key output parameters were within $5 \%$ of the values specified by the manufacturer. An additional GT-POWER model was constructed to evaluate the waste heat recovery mechanism inside the existing engine piston. An exhaust heat exchanger was designed to produce the minimum possible pressure drop, thus minimizing the negative impact of the waste heat recovery mechanism.

Figure 1.4 shows a schematic of the external components associated with the waste heat recovery system. 


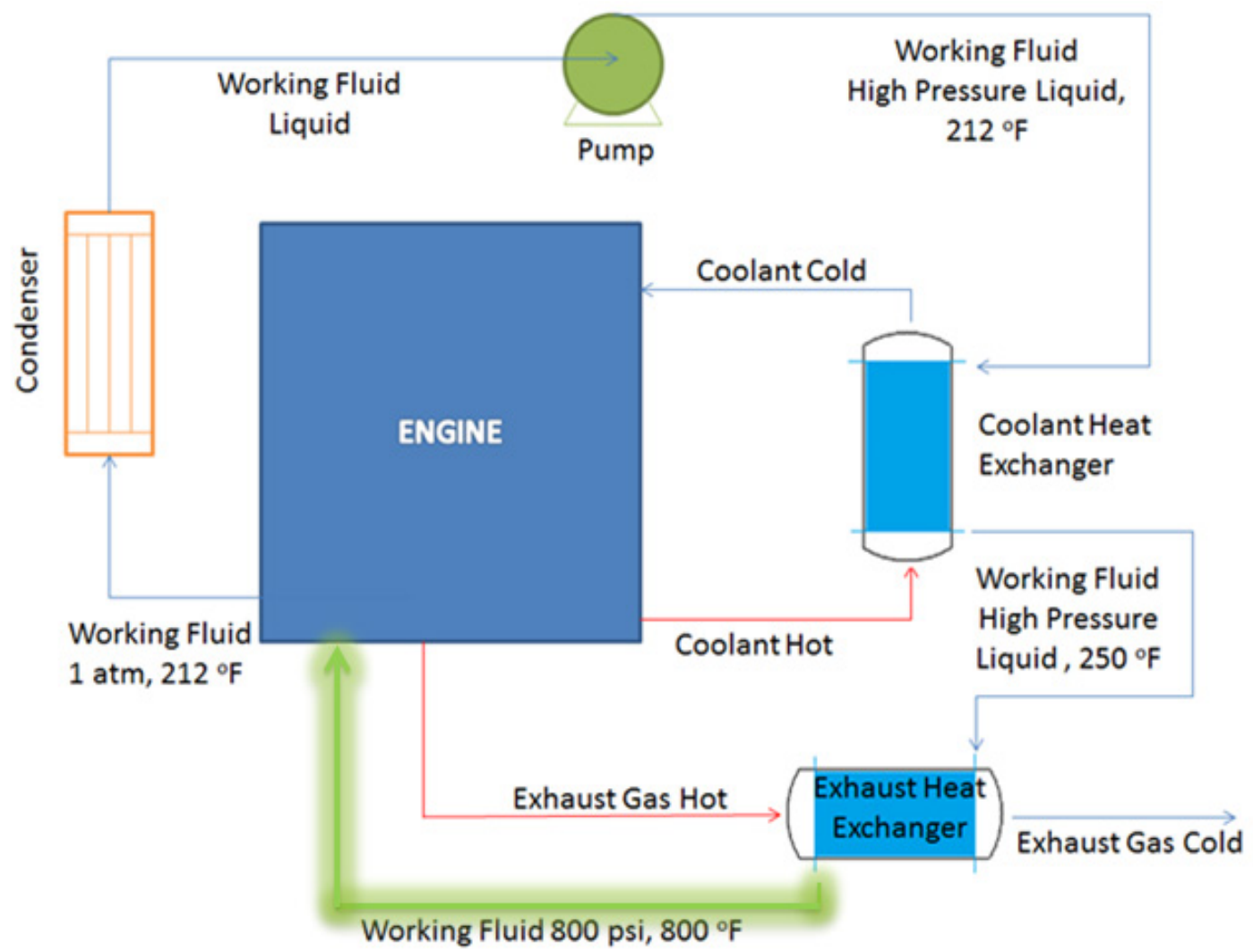

Figure 1.4: Novel waste heat recovery system schematic

There are four primary components within the WHR system:

\subsubsection{Heat exchanger between the coolant system and the working fluid}

This heat exchanger is used to extract the thermal energy from the coolant system and raise the temperature of the working fluid. $100 \%$ propylene glycol replaces the commonly used ethylene glycol/water mixture within the coolant system. This was chosen to achieve an increased coolant temperature without the concern of boiling since the boiling point of propylene glycol, $\left(370^{\circ} \mathrm{F}\right)$ is higher than that of an ethylene glycol/water mixture $\left(225^{\circ} \mathrm{F}\right)[1,2]$. Also, the working fluid had an increased temperature of $250^{\circ} \mathrm{F}$ before entering the exhaust heat exchanger, which reduced the size, back pressure and cost of the heat exchanger. Figure 1.5 shows a schematic of the single pass coolant heat exchanger used in the simulation. 


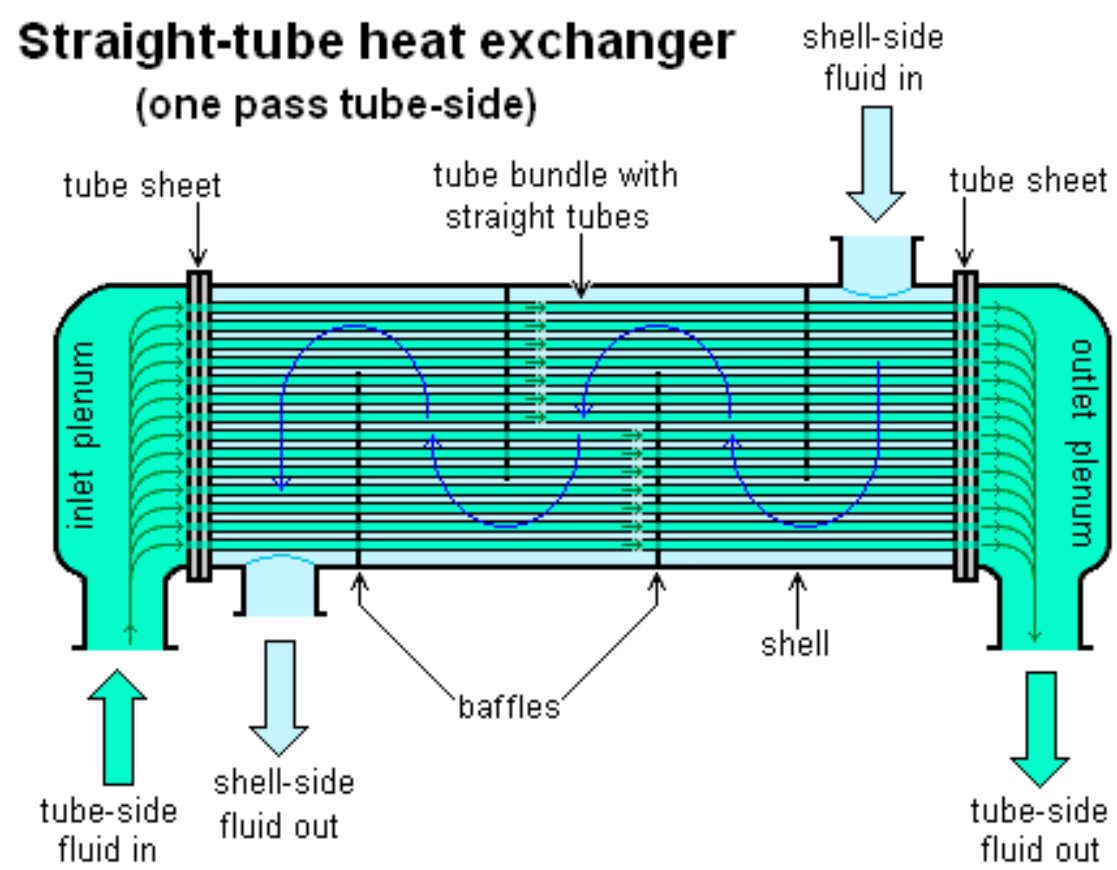

\section{Figure 1.5: Coolant heat exchanger schematic [14]}

The following assumptions and engineering decisions were made related to the coolant heat exchanger $[1,2]$ :

- $100 \%$ propylene glycol was chosen as the working fluid since it will boil at 2 bar pressure and $300^{\circ} \mathrm{F}$.

- Due to the low peak temperature of $250^{\circ} \mathrm{F}$ within the engine coolant, the pressure (approximately 800 psia) of the working fluid entering the coolant heat exchanger was high enough to avoid a phase change from liquid to vapor.

- The mass flow rate of the working fluid within the coolant heat exchanger was assumed to be constant. Due to the multiple-cylinder engine configuration, it reduced fluctuations in the mass flow rate of the working fluid and thus this assumption was believed to be accurate. 


\subsubsection{Heat exchanger between the exhaust system and the working fluid}

This heat exchanger is used to vaporize and superheat the working fluid. For a gas-to-gas heat exchange process, a compact heat exchanger is the optimum choice for the exhaust heat exchanger [4]. A fin - tube type compact heat exchanger which is shown in Figure 1.6 (b) was chosen as the exhaust heat exchanger.

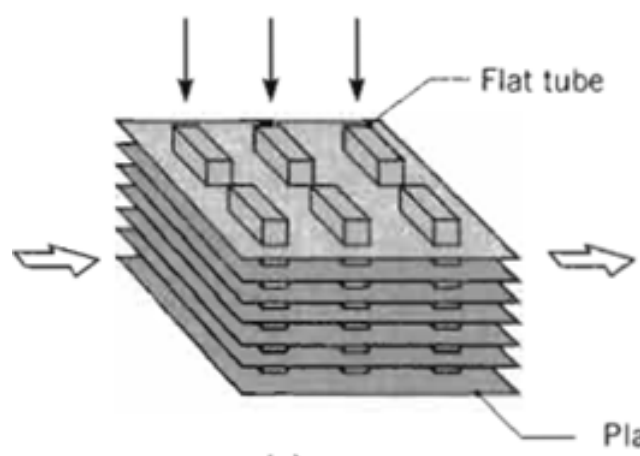

(a)

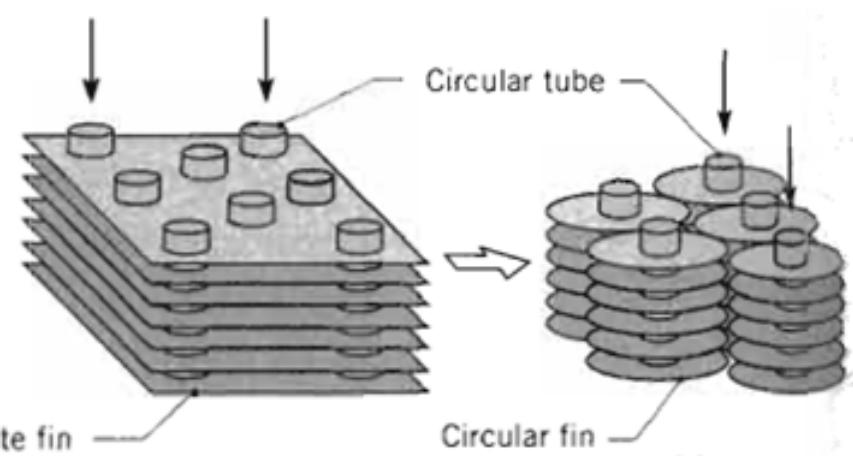

(b) (c)

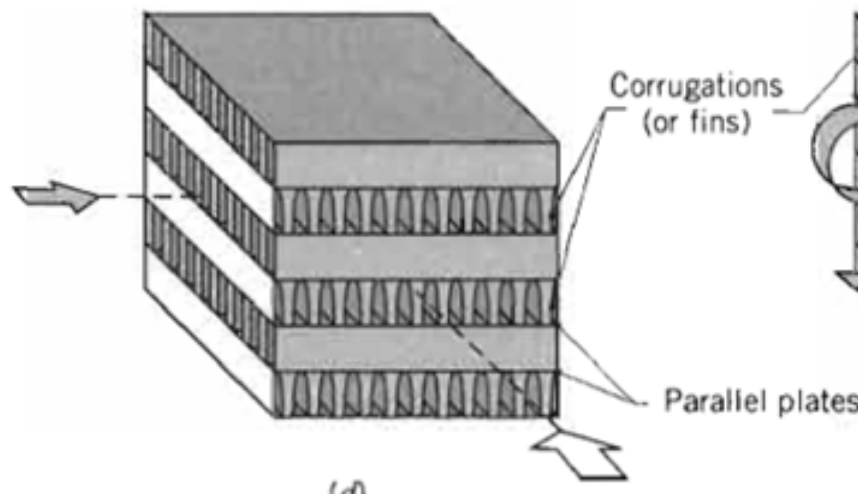

(d)

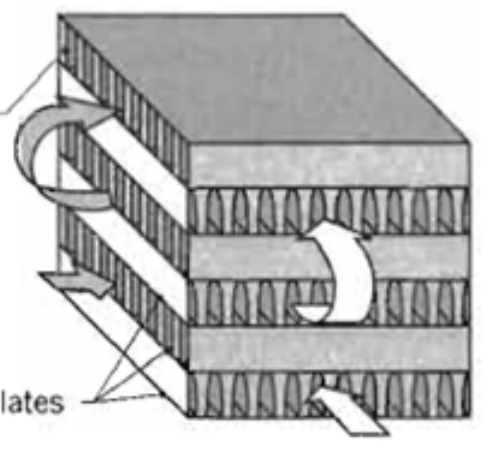

(e)

Figure 1.6: Different types of compact heat exchangers [4]

The following assumptions and engineering decisions were made related to the exhaust heat exchanger $[1,2]$ :

- The working fluid enters this heat exchanger as a saturated liquid, changes to saturated vapor and finally leaves the heat exchanger as a superheated vapor. 
- The maximum temperature of the working fluid was limited to the maximum temperature of the exhaust.

- The back pressure that the engine exhaust stroke must overcome is calculated in the subsequent sections and it varies with the design of the heat exchanger. It is a very important parameter and a heat exchanger with the lowest backpressure is preferred.

\subsubsection{Steam chamber within the modified piston assembly}

The working fluid vapor is allowed to expand in the steam chamber located underneath the piston head. This configuration helps reduce the compression work and the exhaust work, thus increasing the power of the engine.

The following assumptions and engineering decisions were made related to the steam chamber $[1,2]$ :

- The steam chamber was designed to be of zero clearance and zero compression. This was done to achieve nearly instantaneous pressure increase to the inlet levels when the steam admission valve opened. The clearance height was set to 0.02 inches.

- When the steam admission valve closed, the steam chamber volume was increasing and the vapor followed a polytropic expansion process $\left(\mathrm{PV}^{\mathrm{n}}=\right.$ constant). The value of the polytropic exponent (n) was determined from the steam chamber model in GT-POWER.

- To maximize the power generated within the steam chamber, the exhaust steam valve timing was optimized to minimize the pumping work during the steam exhaust cycle.

- A cut - off ratio was defined as the volume of the steam chamber cylinder when the steam admission valve closes divided by the total volume of the steam chamber cylinder at bottom dead center (BDC). A cut - off ratio of 
0.05 was chosen for this analysis, consistent with other steam chamber designs.

- The exhaust steam flows into the condenser which is at atmospheric pressure. This was done to convert the saturated vapor exhaust steam to saturated liquid with ambient air temperature. If the condenser pressure was higher or lower than atmospheric pressure, there would be a reduction in thermal efficiency and the possibility of air leakage into the system.

\subsubsection{Condenser, pump and piping}

The condenser replaces the position of the traditional radiator to provide the required heat transfer to the ambient air.

The following assumptions and engineering decisions were made related to the condenser, pump, and piping $[1,2]$ :

- The inlet pressure of the condenser was set at atmospheric (1 bar).

- To consider pumping losses through the piping, a 5\% pressure drop was assumed between each component.

- The pump increases the pressure of the working fluid to maximize the amount of thermal energy recovered. This helped to maximize the work done during the polytropic expansion in the steam chamber. 


\section{Chapter 2 Background/Literature Review}

Waste heat recovery involving a Rankine cycle utilizes sensible enthalpy from the hot exhaust gases coming out of the engine to heat the working fluid to superheated vapor and then the sensible enthalpy from the vapor is used to obtain useful work. Rankine cycles have been explored by automotive and power generation industry for many years. A review of some of the previous work using Rankine cycles for WHR is discussed below.

Brands, et al. [18] achieved WHR in a six cylinder, 14.5 L, Cummins NTC-400 diesel engine rated at $298 \mathrm{~kW}$ at $2100 \mathrm{RPM}$ by turbo-compounding. This involved the use of a power turbine to recover energy from the exhaust gas. The authors demonstrated a $12.5 \%$ improvement in power and $14.8 \%$ net improvement in fuel economy due to WHR by Rankine cycle turbo-compounding.

Chen, et al. [20] reviewed many methods incorporated by various investigators to improve engine efficiency. They came to the conclusion of a possible multi-stage Rankine cycle with the $1^{\text {st }}$ stage operating on water followed by a $2^{\text {nd }}$ stage operating on R-11 (organic solvent) to recover high temperature exhaust heat and to enable low temperature exhaust WHR respectively. They also predicted a $15 \%$ improvement in efficiency through WHR.

An ORC system operating on trifluoroethanol designed for use with a Class 8, long-haul vehicle diesel engine was tested for improvements in engine efficiency. [21] A $12.5 \%$ increase in highway fuel economy was achieved with this system.

Teng, et al. [22] analyzed a supercritical ORC system of WHR from heavy duty diesel engines. The exhaust WHR was analyzed from the perspectives of the first and second law of thermodynamics. They predicted up to a $20 \%$ improvement in engine power using a supercritical ORC. 
The Rankine cycle efficiency of various wet, dry and isentropic fluids was examined by Chammas, et al. [6]. They presented a concept to recover waste heat from high and low temperature of the exhaust and engine coolant respectively. They concluded that to eliminate the need of a superheating apparatus, the Rankine cycles should operate on dry or isentropic fluids. Simulations predicted a $32 \%$ improvement in fuel economy and also the energy from both exhaust and engine coolant can be recovered to a certain limit (2 $2^{\text {nd }}$ law efficiency).

Stationary IC engines were investigated by Vaja, et al. [23] for WHR using a thermodynamic analysis. They predicted a $12 \%$ improvement in thermal efficiency. Various working fluids were tested and benzene showed the highest improvement. A critical heat exchanger was needed to be designed in their analysis to achieve the predicted results.

The improvement in engine efficiency using Rankine cycles for WHR has been analyzed, simulated and tested by various individuals for many types of engines. A common conclusion obtained from the literature review is that using Rankine cycles for WHR has the potential to improve the overall engine efficiency. Based on the results of the above discussed papers, the current research project of a novel waste heat recovery mechanism for an I.C. engine using an ORC was continued. 


\section{Chapter 3 Experimental Setup}

The Waukesha 16V275GL+ stationary gas compression engine shown in Figure 3.1 was modeled in GT-POWER to simulate the performance parameters of the engine. The simulated model does not exactly match the data given by the company since propriety data such as valve timings and lift at every angle was not obtained.

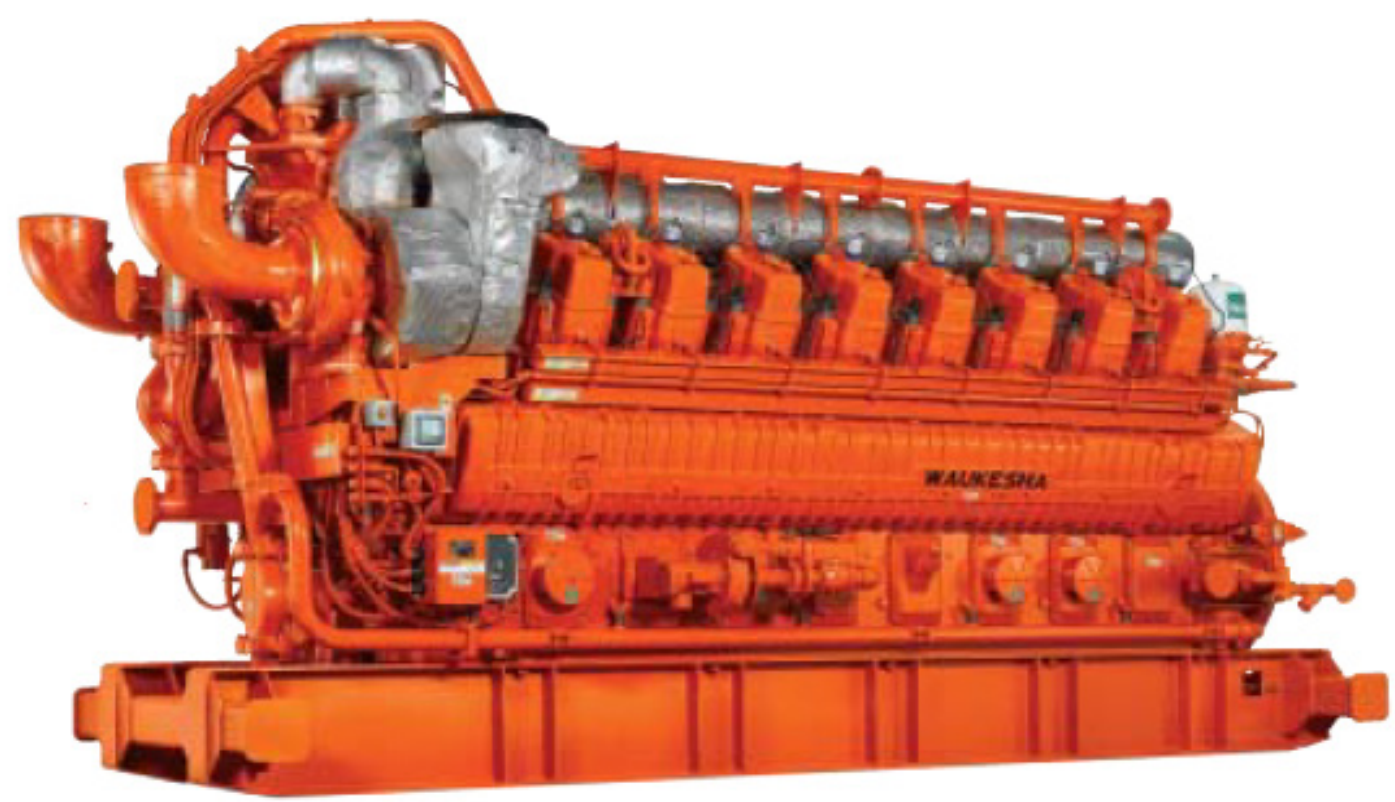

Figure 3.1:Waukesha 16V275GL+ engine [7]

Table 3.1 and Table 3.2 were obtained from the data provided by the manufacturer [7]. The data provided was not sufficient to accurately model the engine without making some assumptions, which will be discussed in the following sections. 
Table 3.1: Performance data of the Waukesha 16V275GL+ engine [7]

\begin{tabular}{|c|c|}
\hline \multicolumn{2}{|c|}{ PERFORMANCE DATA@900 RPM } \\
\hline Power bhp (kWb) & $4350(3244)$ \\
\hline BSFC (LHV) Btu/bhp-hr (kJ/kWh) & $6386(9035)$ \\
\hline NOx g/bhp-hr (mg/Nm3@5\% O2) & $0.5(230)$ \\
\hline CO g/bhp-hr (mg/Nm3@5\% O2) & $1.5(681)$ \\
\hline NMHC g/bhp-hr (mg/Nm3@ @ 5\% 02) & $0.84(386)$ \\
\hline THC g/bhp-hr (mg/Nm3@5\% O2) & $5.6(2574)$ \\
\hline Methane g/bhp-hr (mg/Nm3@ @ \% O2) & $4.76(2188)$ \\
\hline Formaldehyde g/bhp-hr (mg/Nm3 @ 5\% O2) & $0.18(83)$ \\
\hline $\mathrm{CO}_{2} \mathrm{~g} / \mathrm{bhp}-\mathrm{hr}(\mathrm{g} / \mathrm{Nm} 3 @ 5 \% \mathrm{O} 2)$ & $391(180)$ \\
\hline $\mathrm{CO}_{2} \mathrm{e}$ (greenhouse gas) g/bhp-hr (g/Nm3@5\% O2) & $491(226)$ \\
\hline Heat rejection to jacket water Btu/hr*1000 (kW) & $2745(805)$ \\
\hline Heat to lube oil Btu/hr*1000 (kW) & $980(287)$ \\
\hline Heat rejection to intercooler Btu/hr*1000 (kW) & $2688(788)$ \\
\hline Total exhaust heat Btu/hr x $1000(\mathrm{~kW})$ & $10318(3024)$ \\
\hline Heat to radiation $\mathrm{Btu} / \mathrm{hr} \times 1000(\mathrm{~kW})$ & $516(151)$ \\
\hline Induction air flow SCFM $\left(\mathrm{Nm}^{3} / \mathrm{hr}\right)$ & $11702(17624)$ \\
\hline Exhaust gas flow rate $\mathrm{lb} / \mathrm{hr}(\mathrm{kg} / \mathrm{hr})$ & $52623(23870)$ \\
\hline Exhaust stack temperature ${ }^{\circ} \mathrm{F}\left({ }^{\circ} \mathrm{C}\right)$ & $727(386)$ \\
\hline
\end{tabular}


Table 3.2: Technical data of the Waukesha 16V275GL+ engine [7]

\begin{tabular}{|l|c|}
\hline \multicolumn{2}{|c|}{ TECHNICAL DATA } \\
\hline Cylinders & V16 \\
\hline Piston displacement & 17398 cu.in. $(285 \mathrm{~L})$ \\
\hline Compression ratio & $9: 1$ \\
\hline Bore \& stroke & 10.83 ” x 11.81” $(275 \times 300 \mathrm{~mm})$ \\
\hline Jacket water system capacity & 133 gal. $(503 \mathrm{~L})$ \\
\hline Lube oil capacity & 275 gal. $(1040 \mathrm{~L})$ \\
\hline Starting pressure & 150 psi $(10.3 \mathrm{bar})$ \\
\hline Fuel pressure & $45-60$ psi $(3.1-4.1 \mathrm{bar})$ \\
\hline Dimensions $1 \mathrm{x}$ w $\mathrm{x}$ h inch $(\mathrm{mm})$ & $237.4(6026) \times 91.3(2320) \times 126.4 ”(3211)$ \\
\hline Weight lb $(\mathrm{kg})$ & $66,000(29,835)$ \\
\hline
\end{tabular}

\subsection{Modeling of Waukesha 16V275GL+ engine:}

\subsubsection{Fuel consumption}

The fuel consumed by the engine was calculated using the BSFC and power which were provided by the manufacturer.

$$
\text { Fuel consumption }=9035\left(\frac{k J}{k W h}\right) x 3244\left(\frac{k J}{s}\right)=8141.538\left(\frac{k J}{s}\right)
$$

Knowing the lower heating value of the fuel (methane), the mass flow rate of fuel consumption was able to be calculated.

Mass flow rate of fuel consumption $=\frac{8141.538 \mathrm{~kJ} / \mathrm{sec}}{50,000 \mathrm{~kJ} / \mathrm{kg}} \times \frac{1000 \mathrm{~g}}{\mathrm{~kg}}=162.83 \mathrm{~g} / \mathrm{sec}$ Eq. 2

\subsubsection{Intake and exhaust valves}

The diameter of the intake and exhaust valves was not provided by the manufacturer of the engine. It is known that intake valves are typically larger than exhaust valves as it is more difficult to get air into the engine than out of the engine. 
Having information about the bore size of the engine, the size of the intake and exhaust valves was calculated as shown in Figure 3.2.

$$
\begin{aligned}
& \text { Intake valve }=4.25 \text { in }(107 \mathrm{~mm}) \\
& \text { Exhaust valve }=3.60 \mathrm{in}(90 \mathrm{~mm})
\end{aligned}
$$

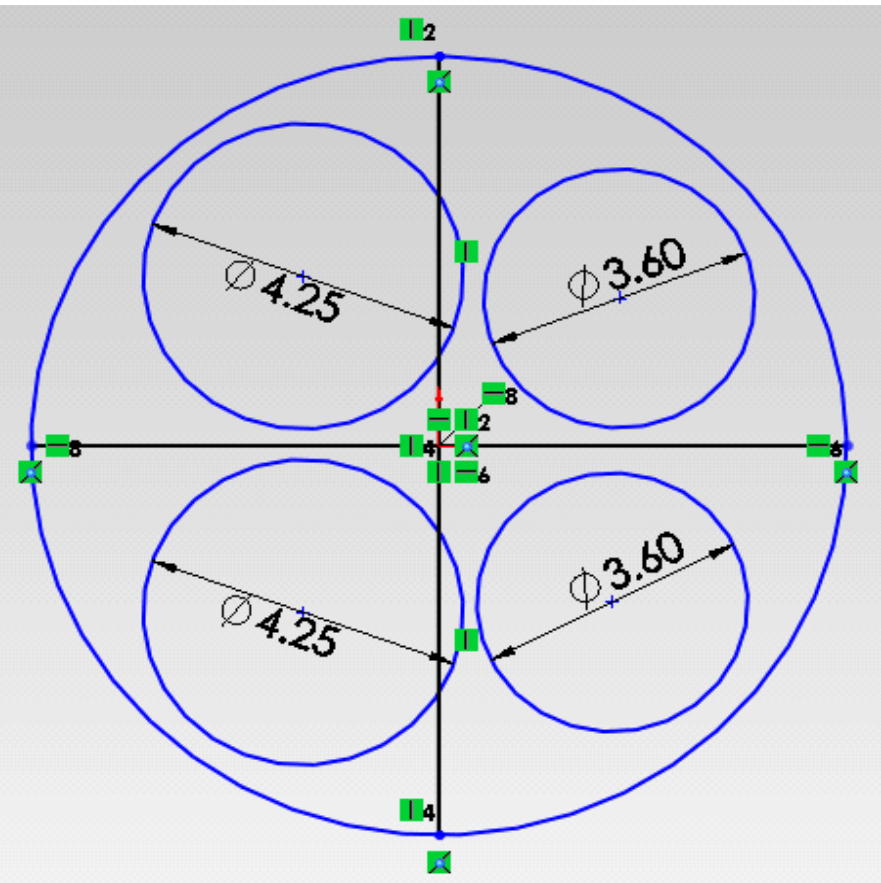

\section{Figure 3.2: Sizing of the intake and exhaust valves}

\subsubsection{Firing order}

The firing order of the engine was obtained by directly contacting the company. The numbers shown in Table 3.3 indicate the number of the cylinder. For example, the first ignition sequence included both cylinders 1 and 9 . 
Table 3.3: Firing order

\begin{tabular}{|c|c|c|c|c|c|c|c|c|}
\hline $\begin{array}{c}\text { Firing } \\
\text { Order }\end{array}$ & 1 & 2 & 3 & 4 & 5 & 6 & 7 & 8 \\
\hline \hline $\begin{array}{c}\text { Cylinder } \\
\text { No. }\end{array}$ & 9 & 10 & 11 & 12 & 13 & 14 & 15 & 16 \\
\cline { 2 - 8 } & 1 & 2 & 3 & 4 & 5 & 6 & 7 & 8 \\
\hline
\end{tabular}

\subsubsection{Compressor, turbine and intercooler}

To model the compressor and turbine of the turbocharger, compressor and turbine maps that existed within GT-POWER were used. Instead of generating new pressure maps according to the engine to be modeled, a multiplier option in GT-POWER was utilized to match the requirements of the engine specifications. A charge air cooler (intercooler) inlet temperature of $327 \mathrm{~K}$ was specified.

\subsubsection{Piping dimensions}

Piping dimensions play an important role in modeling an engine. The efficiency of the engine model decreases with increasing pipe lengths [24]. To obtain an approximate piping dimension, all other parameters were kept constant and only the piping dimensions were changed. All the dimensions for the pipes which include inlet, outlet diameter and length were between $200 \mathrm{~mm}$ to $500 \mathrm{~mm}$.

Data from the manufacturer and assumed/calculated data were used to model the engine. The model was finally optimized to get the desired power output of $4350 \mathrm{HP}$ by varying the cam timing angles. Another model was developed as a single cylinder in GTPOWER having properties of the steam chamber. Its analysis is done in the following sections. 


\subsection{Engine operation}

Figure 3.3 shows a schematic diagram of the modified piston assembly. Note that there are two steam power strokes per two crankshaft revolution.

\subsubsection{Intake stroke}

The residual steam from the previous stroke is expelled into the condenser at 1 atm, $212^{\circ} \mathrm{F}$ (Refer Figure 1.4) where the vapor condenses to liquid. This liquid is pumped to a higher pressure and enters the coolant heat exchanger which increases the temperature of the working fluid. Finally, the working fluid undergoes a phase change in the exhaust heat exchanger and it is superheated to $800 \mathrm{psia}, 747^{\circ} \mathrm{F}$. This superheated vapor is then used in the next stroke.

\subsubsection{Compression stroke}

Recoverable exhaust steam is fed into the steam expansion chamber where it expands and pushes the engine piston upwards. This helps in reducing losses associated with the compression stroke and thus gives more power output.

\subsubsection{Expansion stroke}

During the expansion stroke, the residual steam from the previous stroke is expelled into the condenser and undergoes the same process as that described during the intake stroke.

\subsubsection{Exhaust stroke}

The superheated vapor helps in removing the hot exhaust gases from the engine during the exhaust stroke and the working fluid follows the closed loop again. 


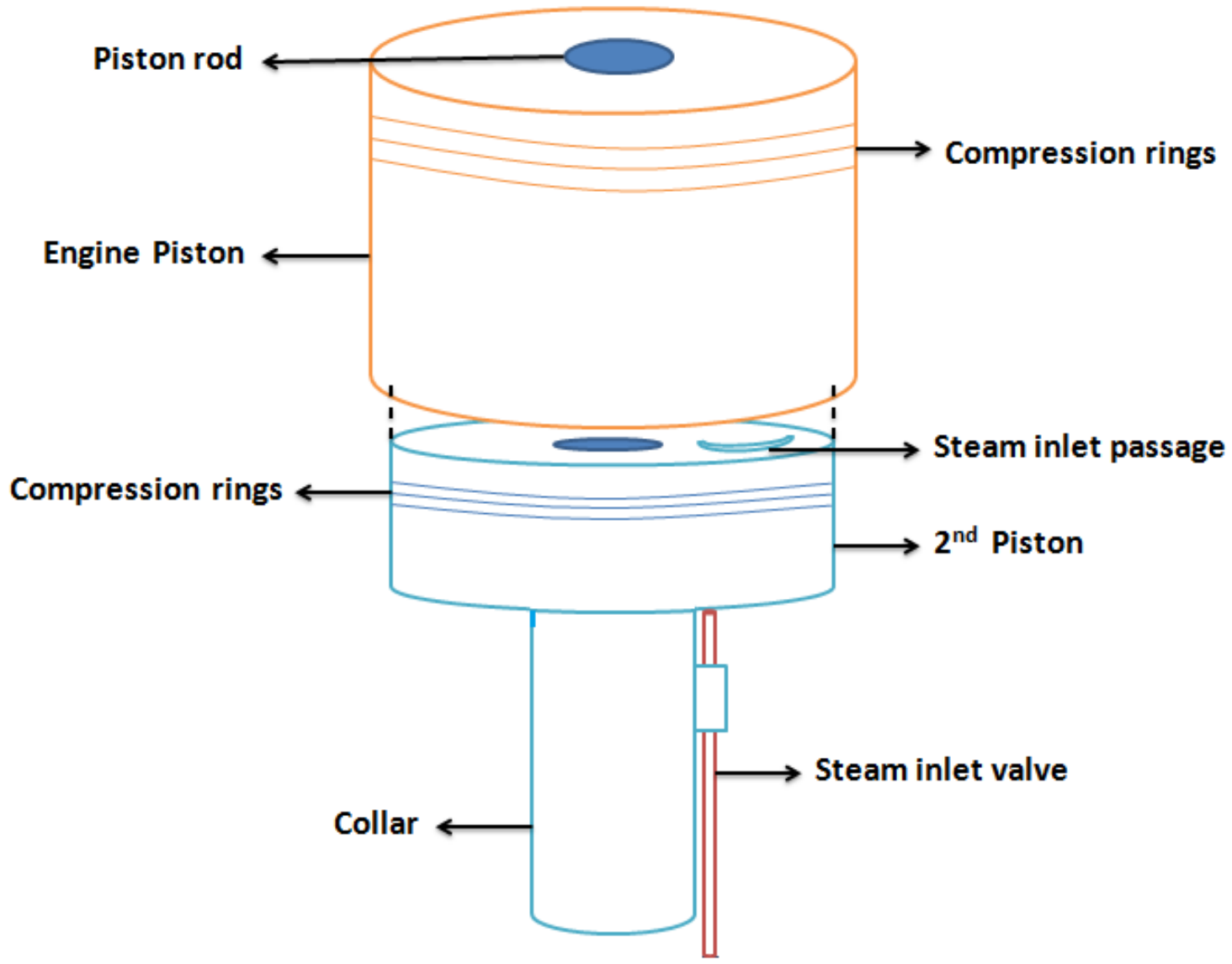

Figure 3.3: Schematic diagram of the modified piston assembly [25] 


\section{Chapter 4 Results}

\subsection{Engine Model Results}

The Waukesha 16V275GL+ engine was simulated at 900 RPM at full load as per design requirements. The following figures show that the simulated engine model is within $5 \%$ error of the data provided by the manufacturer. Figure 4.1 shows the brake power output of the engine from the simulation at 900 RPM.

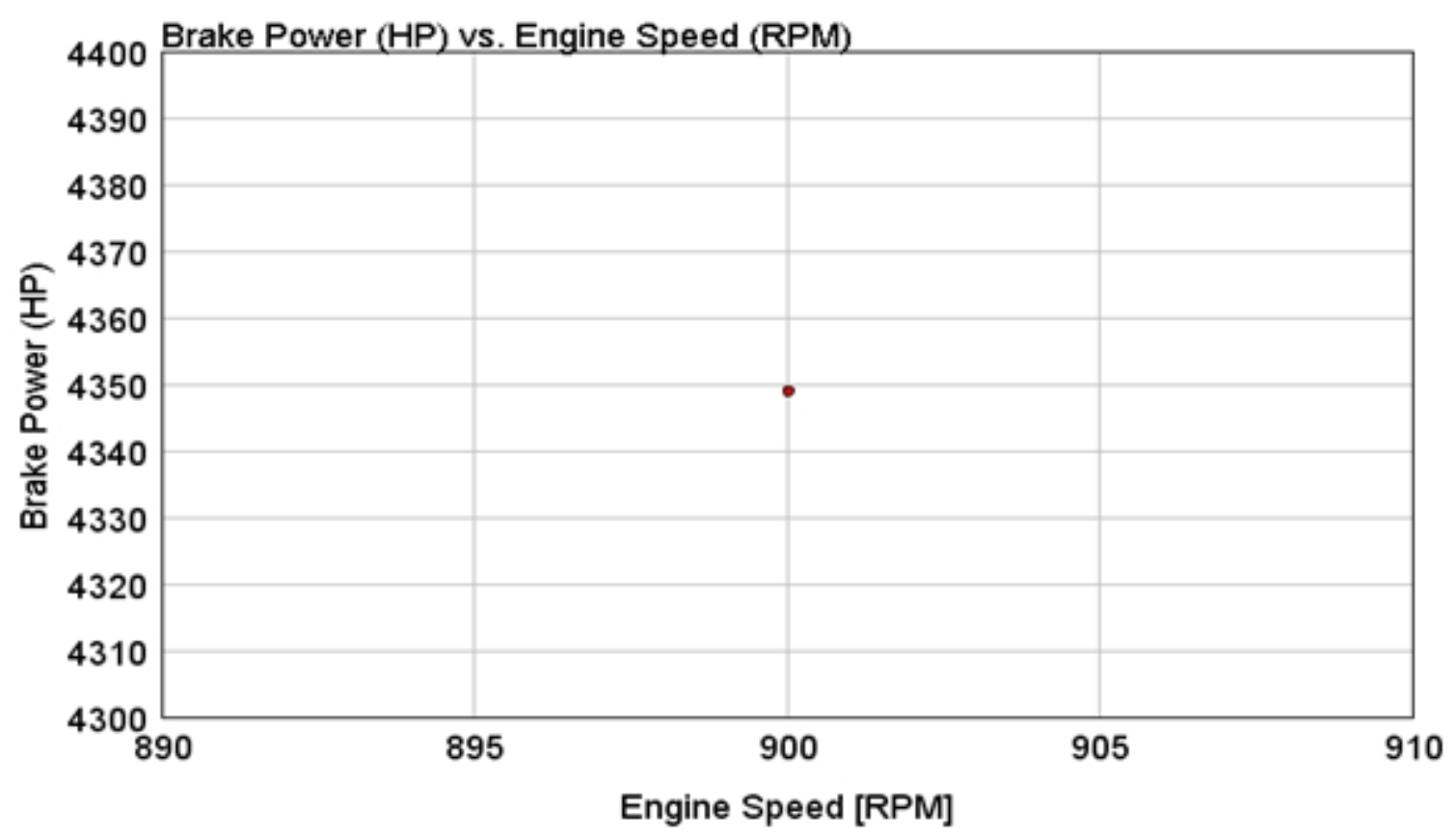

Figure 4.1: GT-POWER simulation results for brake power (HP)

Figure 4.2 shows the specific $\mathrm{CO} 2$ emission level from the simulation at 900 RPM. 


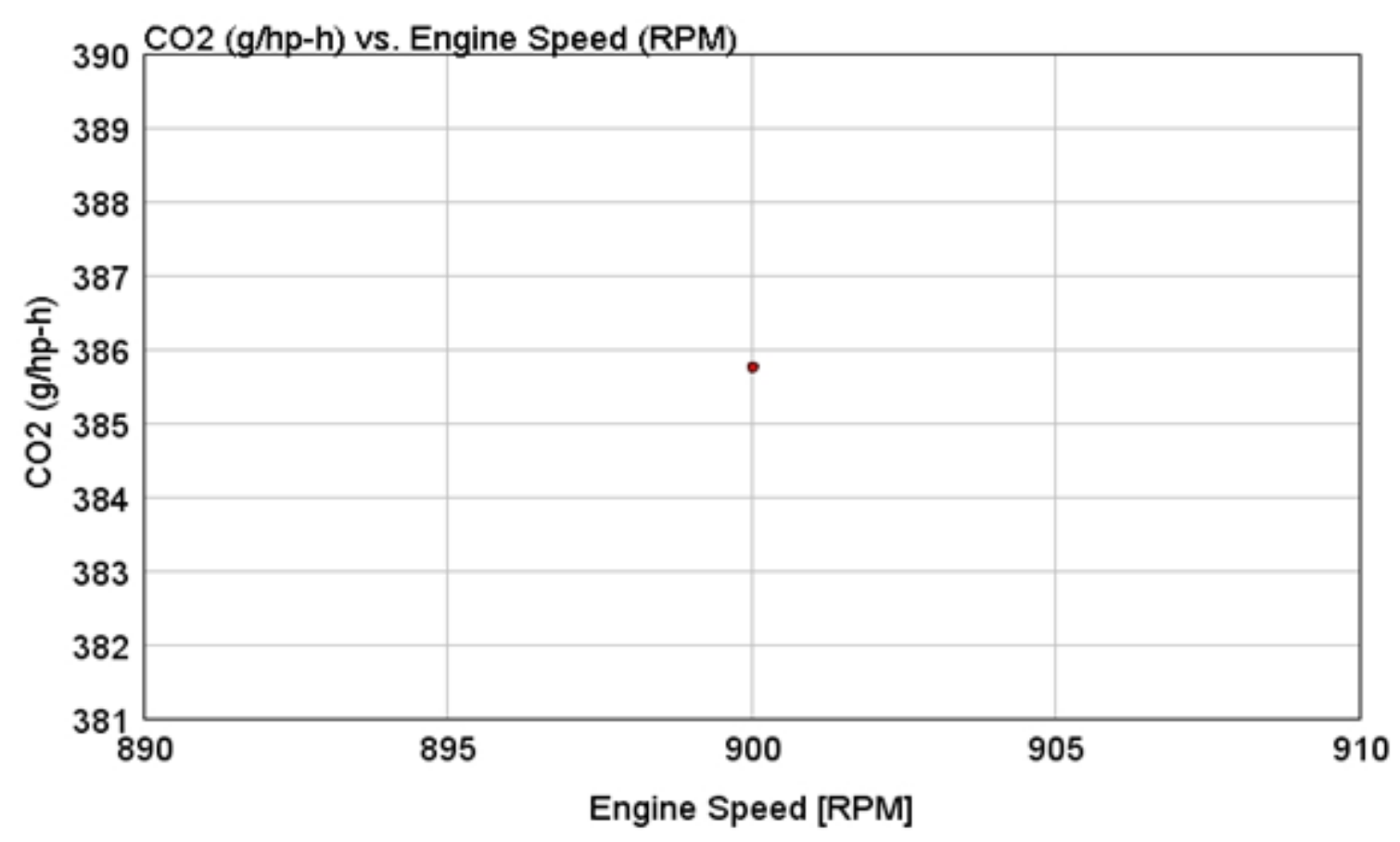

Figure 4.2: GT-POWER simulation results for CO2 (g/hp-h)

Figure 4.3 shows the air flow result for the simulation at 900 RPM and full load.

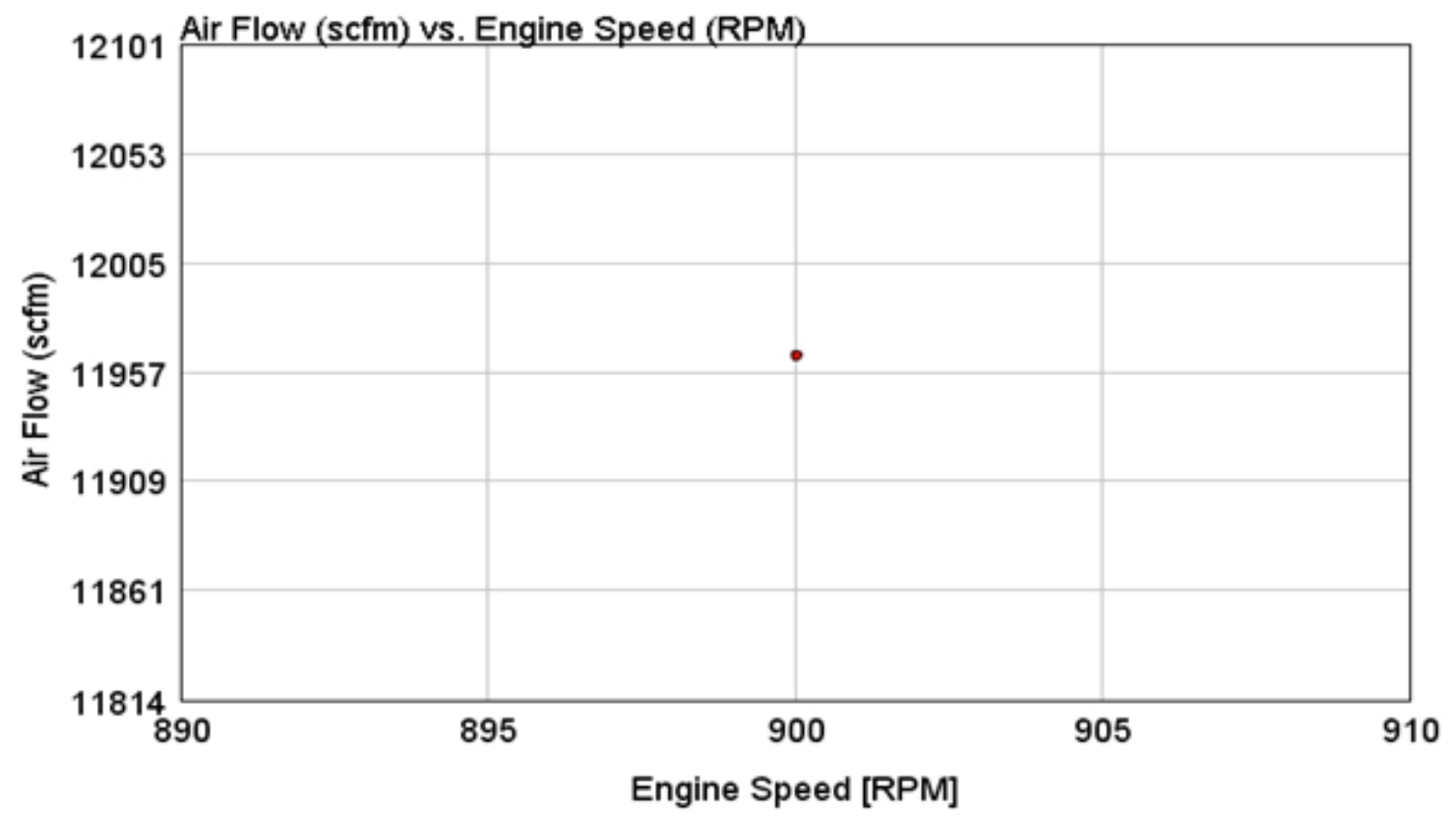

Figure 4.3: GT-POWER simulation results for air flow (scfm) 
Figure 4.4 displays the mass flow rate of the exhaust from the engine at 900 RPM according to the simulation results.

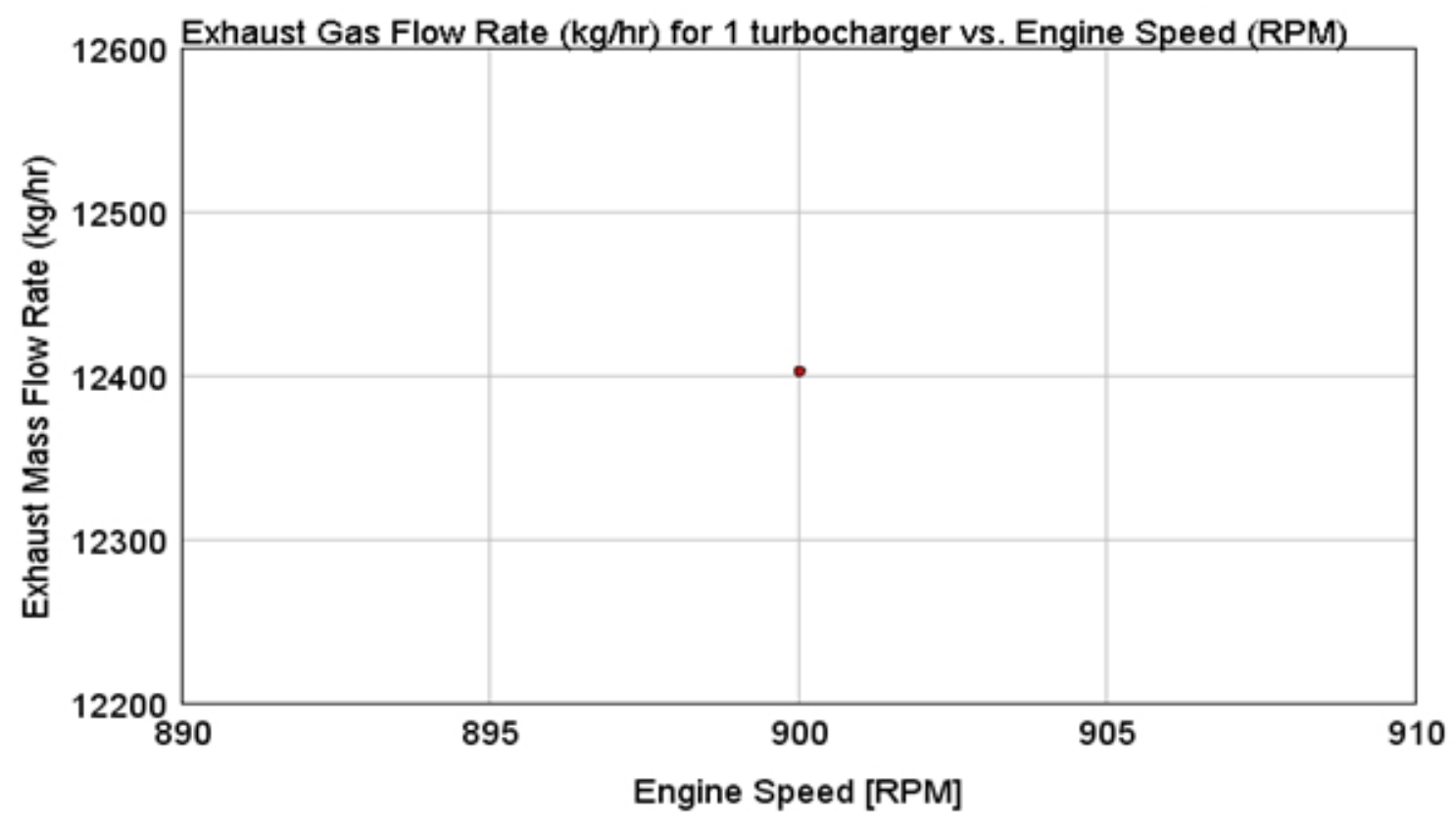

Figure 4.4: GT-POWER results of exhaust gas flow rate $(\mathrm{kg} / \mathrm{hr})$ for 1 turbocharger

Figure 4.5 shows the exhaust gas temperature of approximately $397 \mathrm{C}$ at 900 RPM and full load, from the simulation. 


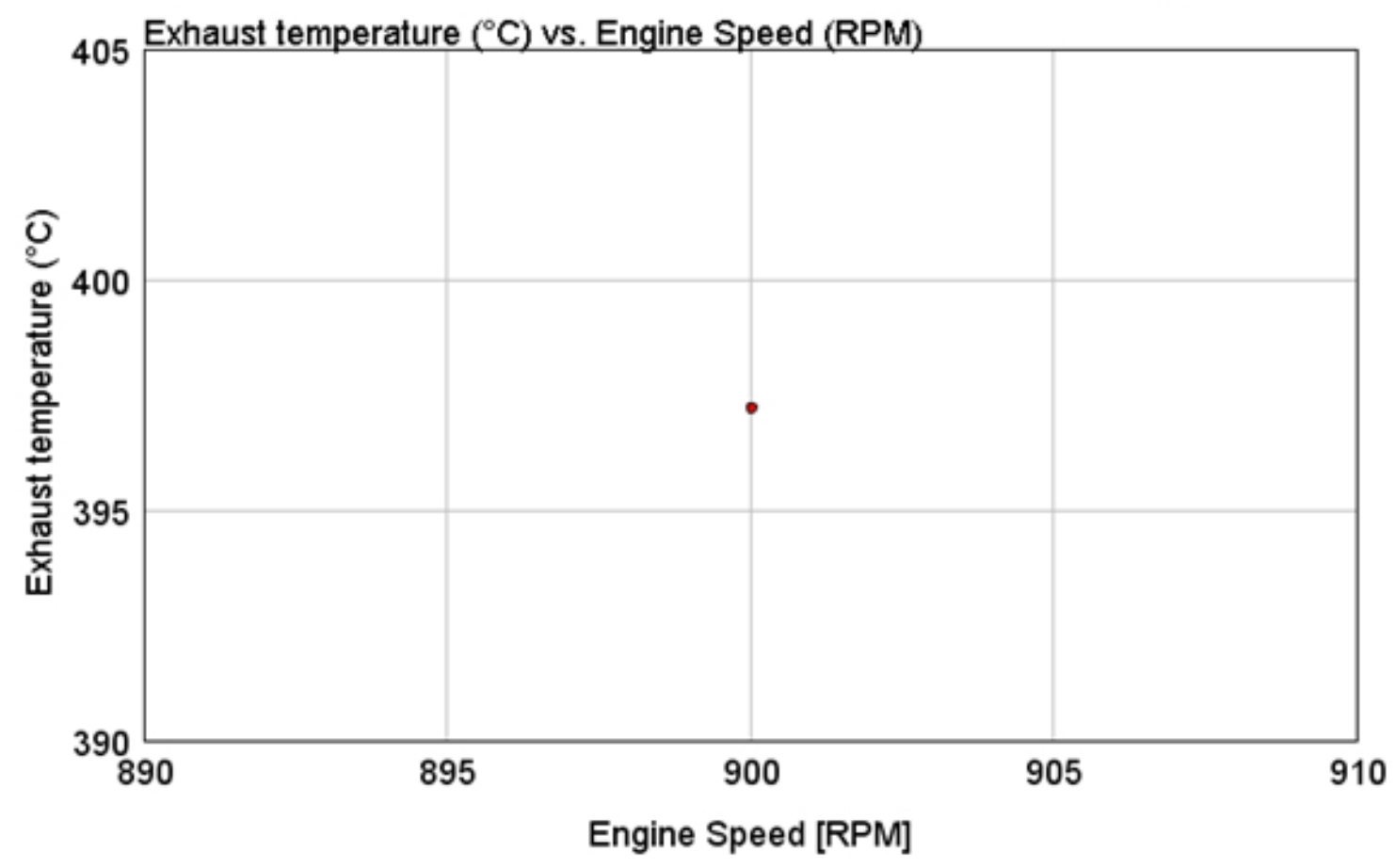

Figure 4.5: GT-POWER results of exhaust temperature $\left({ }^{\circ} \mathrm{C}\right)$

Data from the manufacturer and results from the simulated model were compared and error (\%) was calculated. Table 4.1 shows that the simulated engine model was within $5 \%$ error of the data provided by the manufacturer.

Table 4.1: Error (\%) between the simulated engine model and the actual Waukesha 16V275GL+ engine

\begin{tabular}{|l|c|c|c|}
\hline \multicolumn{1}{|c|}{ Parameters } & $\begin{array}{c}\text { Waukesha } \\
\text { 16V275GL+ }\end{array}$ & Simulated Model & Error (\%) \\
\hline Power (kW) & 4350 & 4349 & 0.023 \\
\hline CO2 emissions (g/hp-hr) & 391 & 386 & 1.3 \\
\hline Air flow (scfm) & 11702 & 11965 & 2.2 \\
\hline Exhaust gas flow rate $(\mathrm{kg} / \mathrm{hr})$ & 23870 & 24812 & 3.9 \\
\hline Exhaust temperature $\left({ }^{\circ} \mathrm{C}\right)$ & 386 & 397 & 2.9 \\
\hline
\end{tabular}




\subsection{Analysis of the Steam Chamber}

A single steam cylinder model was created in GT-POWER having the required properties of the steam chamber. During the steam power stroke, the steam chamber undergoes a polytropic expansion process, $\mathrm{PV}^{\mathrm{n}}=\mathrm{C}$, where $\mathrm{n}$ and $\mathrm{C}$ are polytropic exponent and constant, respectively. The value of ' $n$ ' was determined from GT-POWER and it was found to be between 1.27 and 1.28 for the Waukesha 16V275GL+engine.

For an isentropic process, the specific heat ratio $\mathrm{k}=\mathrm{Cp} / \mathrm{Cv}$ of steam was determined to be:

$$
(0.445(\mathrm{Btu} /(\mathrm{lb}-\mathrm{R}))) /(0.335(\mathrm{Btu} /(\mathrm{lb}-\mathrm{R})))=1.328
$$

The value of ' $n$ ' should be closer to ' $k$ ' because a value of 1 would indicate a slow process with large amounts of heat transfer [1]. The steam inlet valve was opened for a duration of 24 crank angle degrees (CAD) and steam at $747^{\circ} \mathrm{F}$ and 800 psia was dispersed into the steam chamber. The following section describes the various properties of the steam chamber. 


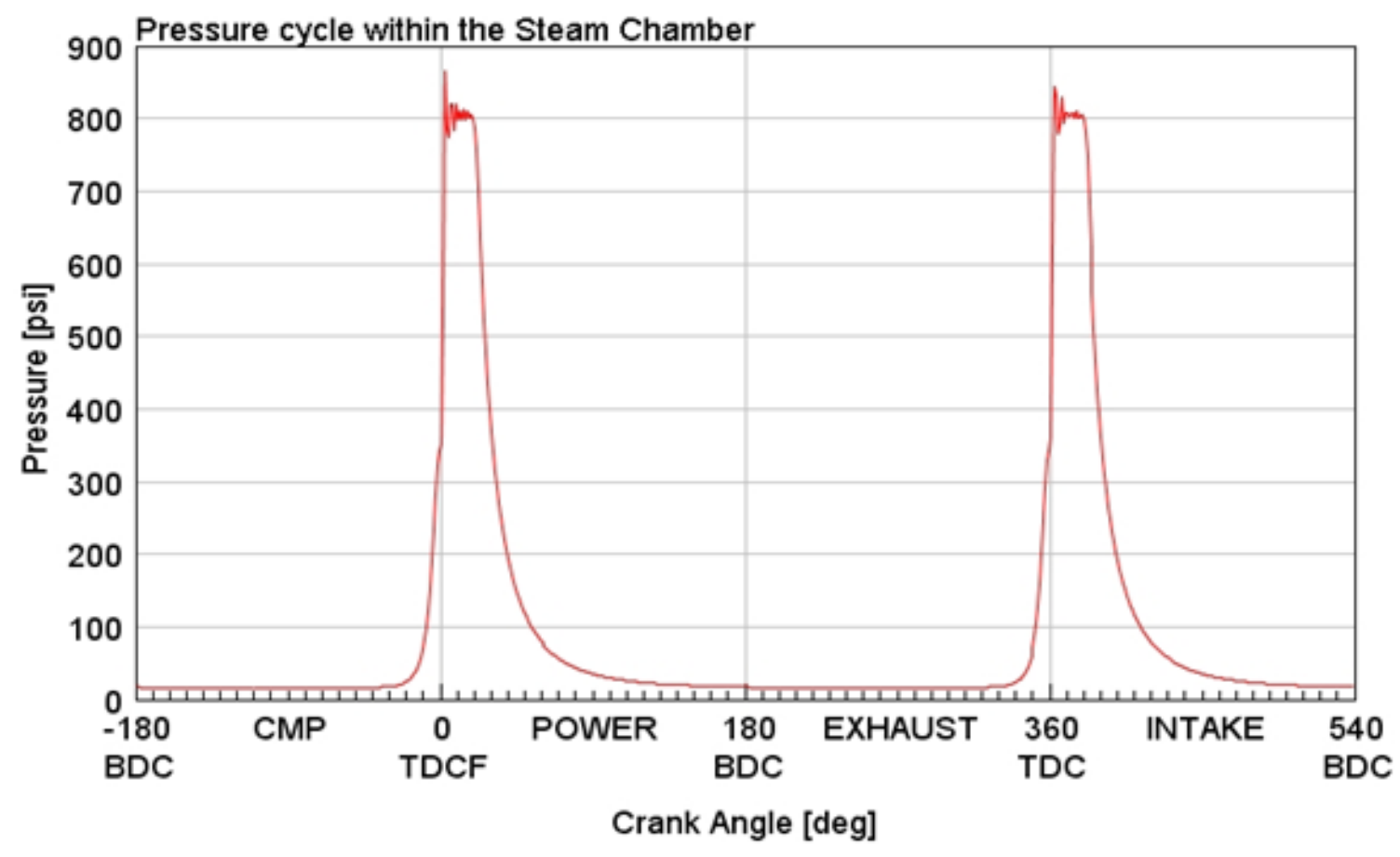

Figure 4.6: Pressure cycle with 2 steam power cycles every 2 crankshaft revolutions

Figure 4.6 shows the pressure variation inside the steam chamber for the entire $720 \mathrm{CAD}$ and the required pressure of 800 psia is observed. 


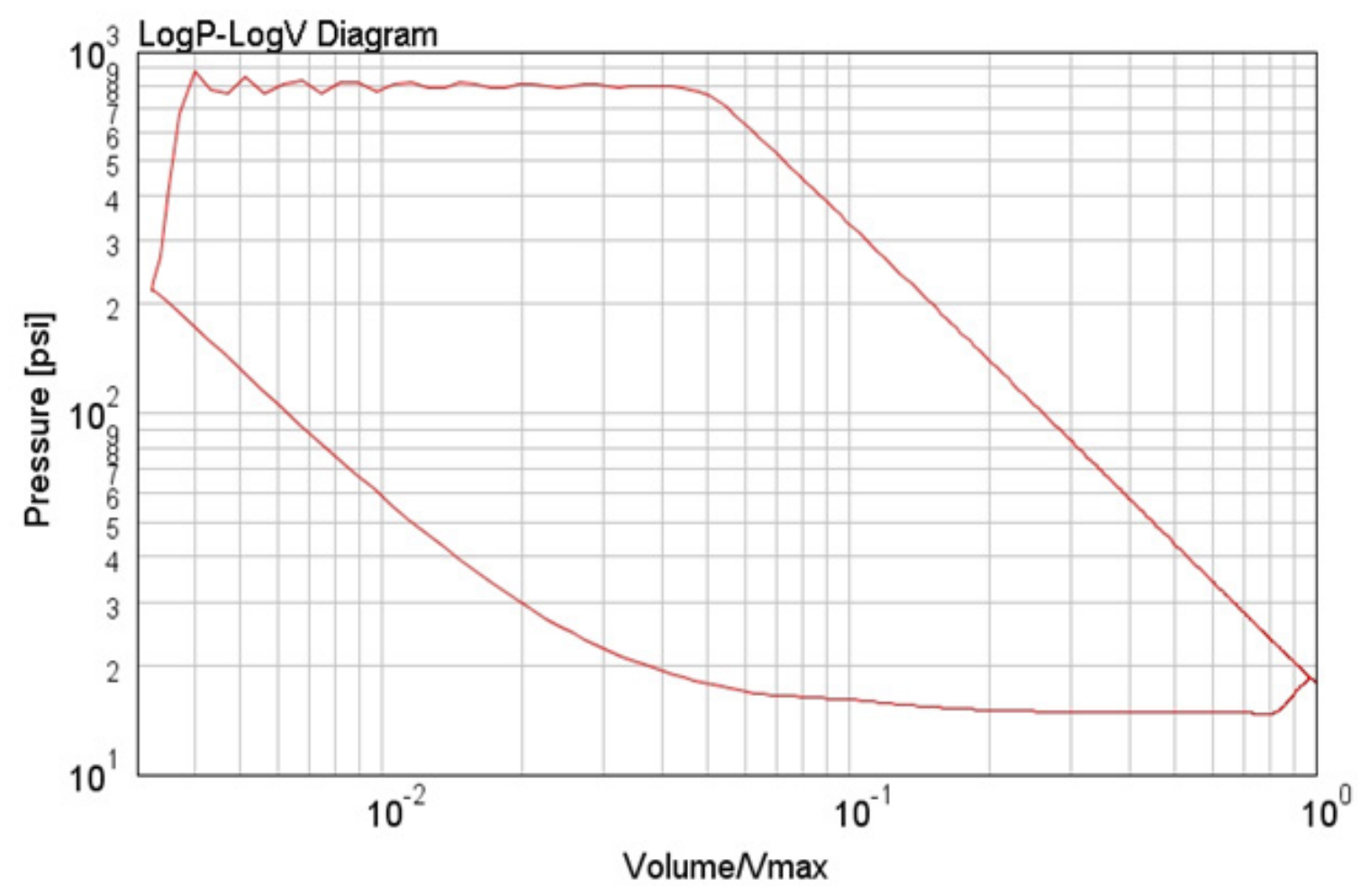

Figure 4.7: $\log P$ vs. $\log V$ for the steam chamber

Figure 4.7 shows the variation of pressure and volume inside the steam chamber on logarithmic coordinates. The slope of the expansion line was calculated after the inlet valve closes, $\mathrm{V} / \mathrm{V}_{\max }=0.05$. It was calculated to be 1.28 . The slope can also be found directly from GT-POWER.

\subsubsection{Optimization of valve timings}

The steam chamber was designed with two inlet and two outlet valves. This was done to reduce the maximum lift requirements due to the required short lift durations. [2]

\subsubsection{Inlet steam valve:}

To attain a cutoff ratio of $5 \%$, the inlet steam valve was set to open at top dead center fired (TDCF) for a duration of 24 crank angle degrees. Due to the very short duration (24 CAD), this lift profile would not be possible in an actual engine due to excessive valve acceleration. 


\subsubsection{Exhaust steam valve:}

For the exhaust steam valve, the GT-POWER model was optimized to produce maximum power. Figure 4.8 shows the lifts profiles for both the intake and exhaust valves.

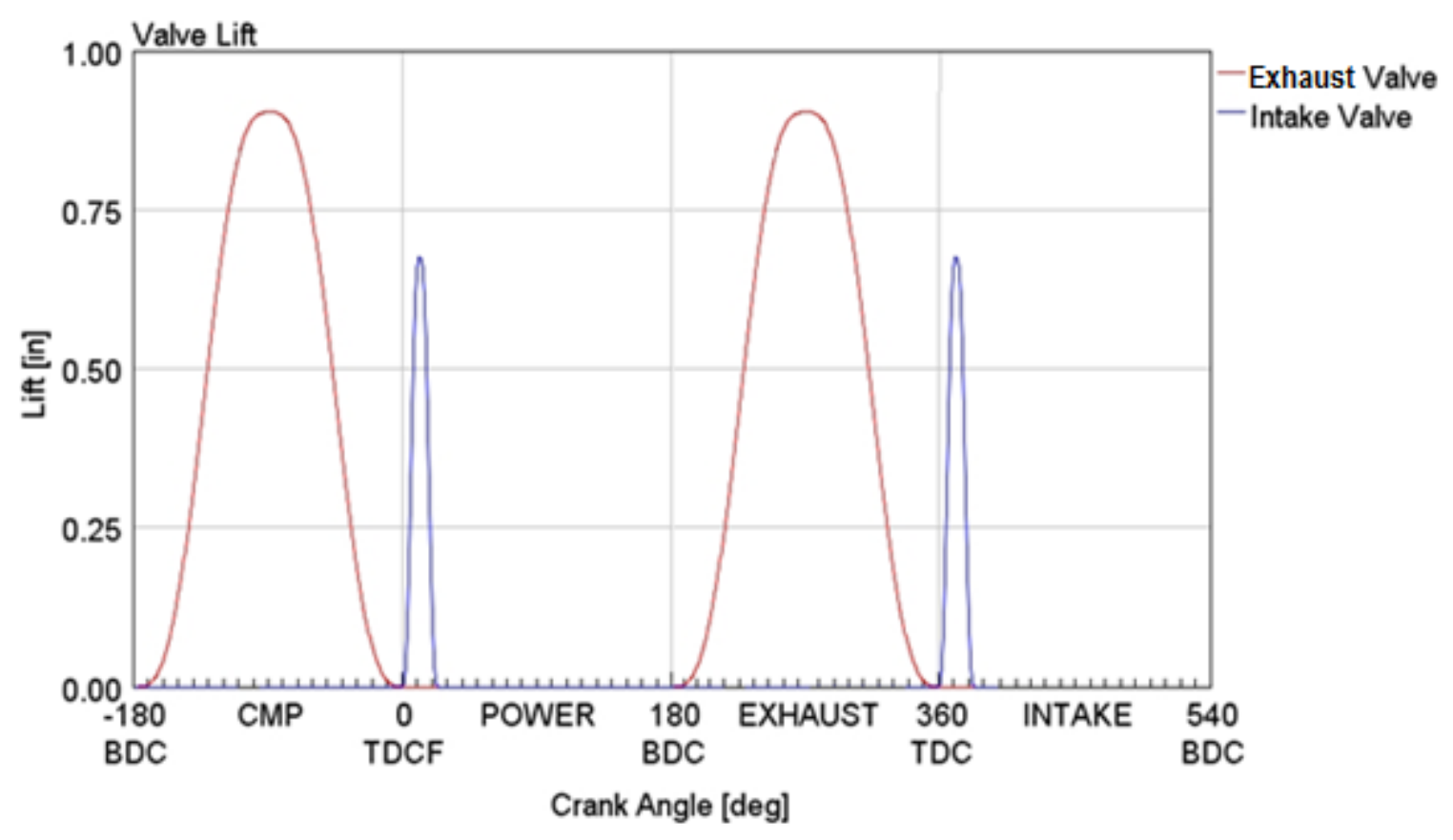

Figure 4.8: Intake and exhaust valve lift profiles

Figure 4.9 shows that the model was optimized to make sure that there was no backflow of working fluid from the condenser to the steam chamber. This phenomenon occurs only when the pressure inside the steam chamber falls below the atmospheric pressure which was the current pressure inside the condenser. 


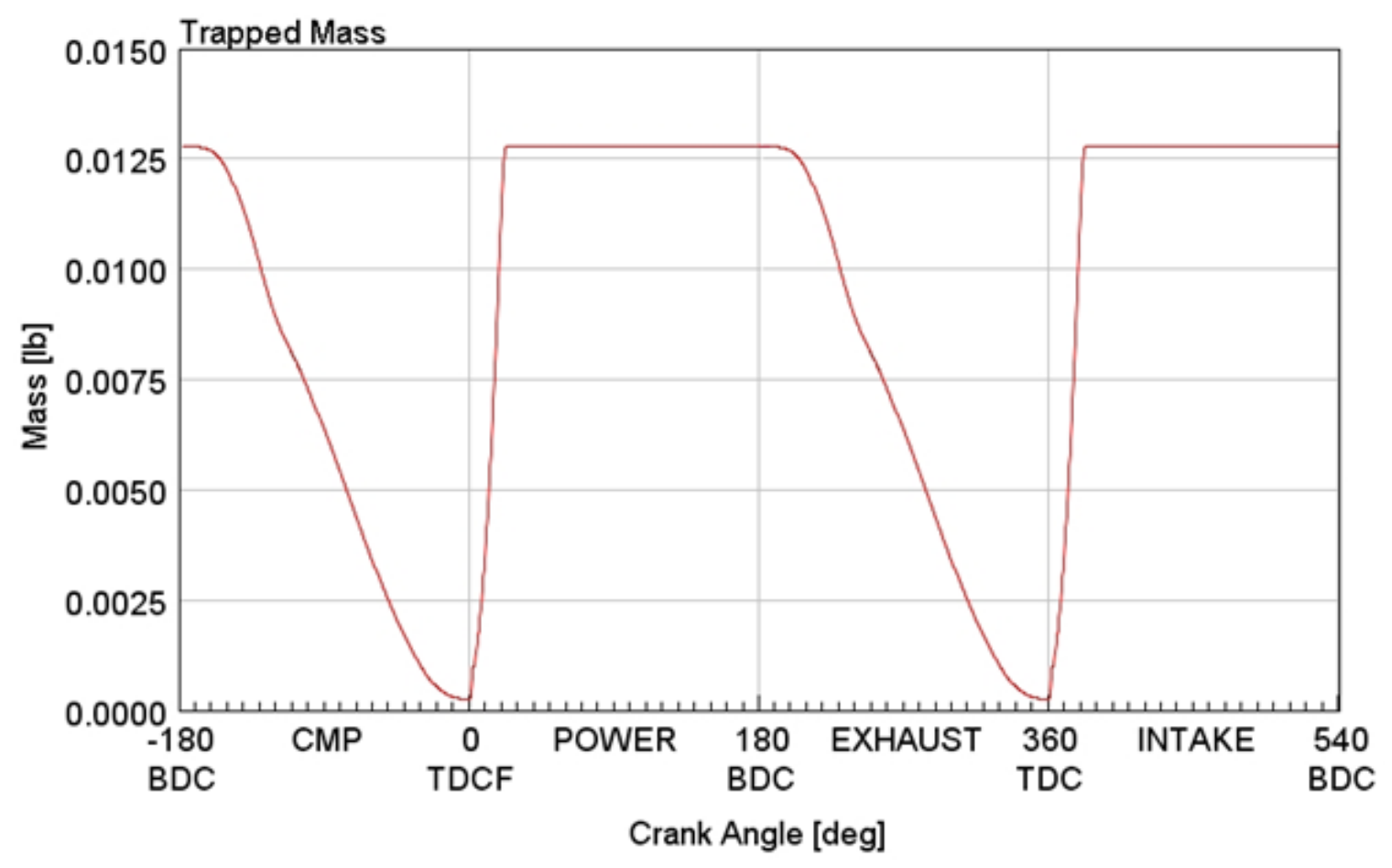

Figure 4.9: Trapped mass inside the steam chamber

Figure 4.10 combines the steam intake valve and the steam exhaust valve lift profiles with the trapped mass inside the steam chamber. Note that the steam exhaust valve closes at $360 \mathrm{TDC}$ as this proves out to be the crank angle for the maximum power generated. 


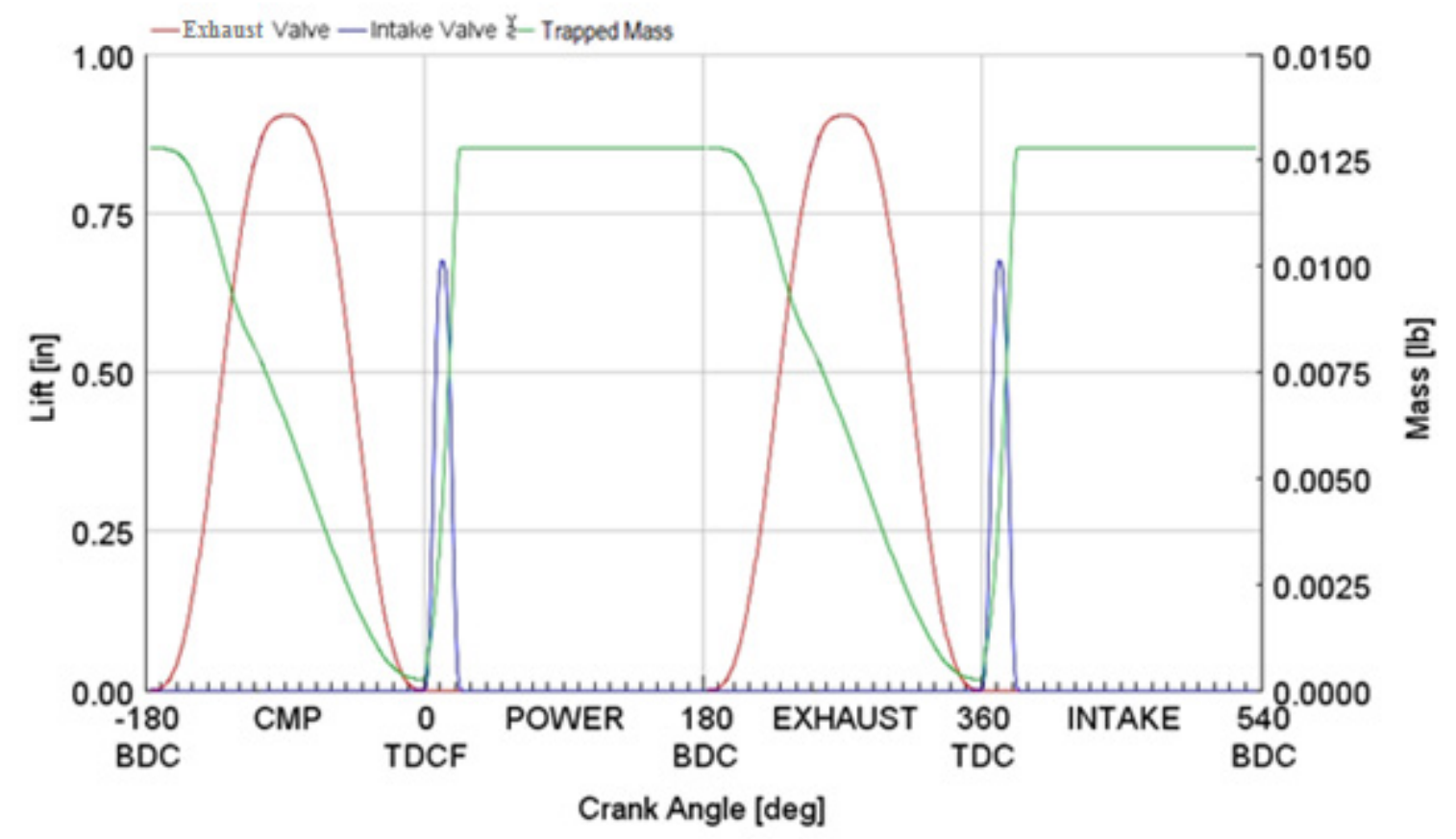

Figure 4.10: Intake and exhaust lift profiles combined with the trapped mass within the steam chamber

The steam chamber was designed and simulated to make sure that the steam entering the steam chamber was at $800 \mathrm{psia}, 747^{\circ} \mathrm{F}$. The exhaust and inlet valves had lifts of approximately 0.9 in and 0.7 in respectively. The trapped mass within the steam chamber was $0.0126 \mathrm{lb}$. Due to the optimization of the steam chamber model for maximum power output, there was no backflow of working fluid into the condenser. 


\section{Chapter 5 Conclusions and Future Work}

\subsection{Conclusions}

The goal of this project was to quantify the improvement in brake fuel conversion efficiency of a large stationary IC engine. The proposed project was evaluated through simulation with GT-POWER. A Waukesha 16V275GL+ stationary spark ignition engine was simulated and studied in GT-POWER with respect to a novel waste heat recovery system.

An additional steam chamber model was built in GT-POWER to meet the requirements of the steam entering the steam chamber. An exhaust heat exchanger was designed to produce the minimum possible pressure drop, thus minimizing the negative impact of the waste heat recovery mechanism.

With the implementation of a piston-in-piston design, calculations show that there is a measureable improvement in the overall efficiency of the engine. There was enough waste heat which was recovered and used to result in an increase of $177 \mathrm{~kW}$ (241 HP) with a $4.53 \%$ increase in brake fuel conversion efficiency.

According to the cost of natural gas as per industry standards $(\$ 5 / \mathrm{cu}$. $\mathrm{ft})$, the total cost of fuel that is required to run the Waukesha $16 \mathrm{~V} 275 \mathrm{GL}+$ natural gas stationary engine is $\$ 1,266,303.393$. With the use of the novel WHR system, this cost would reduce to $\$ 1,241,972.43$ resulting in a profit of $\$ 24,330.96$

Assuming an ideal process (Carnot cycle), the power that could be generated is equal to $1203 \mathrm{hp}$ with an overall brake fuel conversion efficiency of $27.65 \%$.

\subsection{Future Work}

The steam inlet and exhaust valves were set to open inwardly into the steam chamber. Future work will be able to modify this design by changing the orientation of the valves to open outwardly from the steam chamber. This would cause changes in the thermodynamic properties of the working fluid. Validation of the novel WHR system 
during transient conditions and condensation of water within the steam chamber needs further testing. This report does not take into account the changes that would take place if the steam entering the steam chamber is not at $800{ }^{\circ} \mathrm{F}$ and 800 psia. It was assumed constant as the Waukesha 16V275GL+ runs at only one speed (900 RPM) and full load.

The simulated model results will be different from the practical use of the novel WHR system. A small scale prototype incorporating this concept would be beneficial. 


\section{Bibliography}

1. Miers, S.A., Armstead, J.R., Final Report - Simulation Analysis of Automotive Waste Heat Recovery with DYNAMAXTM Technology, June 16th, 2011.

2. Miers, S.A., Armstead, J.R., Supplemental Report - Simulation Analysis of Automotive Waste Heat Recovery with DYNAMAXTM Technology, August 5th, 2011.

3. Cengel, Y.A. and M.A. Boles, Thermodynamics An Engineering Approach. 6th ed. 2008.

4. Incropera, F. P., Dewitt, D. P., Bergman T. L., Lavine, A.S., Fundamentals of Heat and Mass Transfer, 6th ed. 2007.

5. Mori, M., et al., Current Possibilities of Thermoelectric Technology Relative to Fuel Economy. SAE International, 2009 (2009-01-0170).

6. Chammas, R.E. and D. Clodic, Combined Cycle for Hybrid Vehicles. SAE International, 2005 (2005-01-1171).

7. Waukesha 16V275GL+ specification sheet [cited 2010; Available from: http://www.dresserwaukesha.com/documents/7116_1011_16V275GLplus_specsheet.pdf

8. Organic Rankine Cycle (ORC) http://www.orcycle.be/index.php/en/orctheorie.

9. HUNG, T.C., T.Y. SHAI and S.K. WANG, A Review of Organic Rankine Cycles (ORCs) for the Recovery of Low-Grade Waste Heat Energy, 1992. 22(7): p. 661-667.

10. Liu, B.-T., K.-H. Chien, and C.-C. Wang, Effect of Working Fluids on Organic Rankine Cycle for Waste Heat Recovery. Energy, 2004. 29: p. 1207-1217.

11. Crane, D.T. and L.E. Bell, Design to Maximize Performance of a Thermoelectric Power Generator with a Dynamic Thermal Power Source. Journal of Energy Resources Technology, 2009. 131. 
12. Schuster, A., et al., Energetic and Economic Investigation of Organic Rankine Cycle Applications. Applied Thermal Engineering, 2009. 29: p. 1809 - 1817.

13. Gamma - Technologies definition, http://www.gtisoft.com/

14. Shell and tube heat exchanger [cited 2011; Available from:

http://en.wikipedia.org/wiki/Shell_and_tube_heat_exchanger].

15. Wojciechowski, K.T., et al., Comparison of Waste Heat Recovery Mechanisms from the Exhaust of a Spark Ignition and a Diesel Engine. Journal of Electronics Materials, 2009.

16. Heywood, J. B., "Internal Combustion Engine Fundamentals", 1988.

17. Mago, P.J, Srinivasan, K.K., Exhaust Waste Heat Recovery From Stationary Engines Using Organic Rankine Cycles, March 2, 2010 [ Available from:

http://engineeringcases.knovelblogs.com/2010/03/02/exhaust-waste-heat-recovery-fromstationary-engines-using-organic-rankine-cycles/]

18. Brands MC, Werner JR, Hoehne JL, Kramers S. Vehicle testing of Cummins turbocompound diesel engine, SAE Paper No. 810073, 1981.

19. Srinivasan, K.K., Mago, P.J., Krishnan, S.R., Analysis of exhaust waste heat recovery from a dual fuel low temperature combustion engine using an Organic Rankine Cycle, Energy, Volume 35, Issue 6, June 2010, Pages 2387-2399.

20. Chen SK, Lin R. A review of engine advanced cycle and Rankine bottoming cycle and their loss evaluations, SAE Paper No. 830124, 1983.

21. DiBella FA, DiNanno LR, Koplow MD. Laboratory and on-highway testing of diesel organic Rankine compound long-haul vehicle engine, SAE Paper No. 830122, 1983. 
22. Teng H., Achieving high engine efficiency for heavy-duty diesel engines by waste heat recovery using supercritical organic-fluid Rankine Cycle, SAE Paper No. 2006-013522, 2006.

23. I. Vaja, A. Gambarotta, Internal combustion engine (ICE) bottoming with organic rankine cycles (ORCs), Energy, 35 (2) (2010), pp. 1084-1093.

24. Kesgin, U., Study on the design of inlet and exhaust system of a stationary internal combustion engine, Energy Conversion and Management 46 (2005) 2258-2287

25. Kopeliovich, D., Bearings in internal combustion engines, http://www.substech.com/dokuwiki/doku.php?id=bearings_in_internal_combustion_engi nes 


\section{Appendix A}

\section{A.1 Calculations}

Exhaust gas properties were determined from GT-POWER at 900 RPM and full load.

\section{A.1.1 Exhaust gas properties}

Temperature of the exhaust gas, $\quad \mathrm{T}_{\text {high_exhaust }}=747\left({ }^{\circ} \mathrm{F}\right)$

Mass flow rate of the exhaust gas, $\quad \dot{m}_{\text {exhaustgas }}=\frac{27350.516\left(\frac{l b}{h r}\right)}{\frac{3600(s)}{1(h r)}}=7.597\left(\frac{l b}{s}\right)$

Specific heat of the exhaust gas, $\quad \mathrm{C}_{\mathrm{p}_{-} \text {exhuastgas }}=0.2724157\left(\frac{B T U}{l b *^{\circ} \mathrm{F}}\right)$

The exit temperature of both the incoming working fluid and exhaust gas to and from the exhaust heat exchanger was assumed to be $250\left({ }^{\circ} \mathrm{F}\right)$. Practically, this is not possible unless the heat exchanger was infinitely long. The heat exchanger was assumed to be $80 \%$ efficient.

\section{A.1.2 Waste heat recovery from the exhaust heat exchanger}

$$
\begin{aligned}
& \mathrm{WHR}_{\text {exhaust }}=\dot{m}_{\text {exhaustgas }} * \mathrm{C}_{\mathrm{p}_{-} \text {exhaustgas }} * \Delta \mathrm{T} * \eta_{\text {heat_exchanger }} \\
& \mathrm{WHR}_{\text {exhaust }}=27350.516\left(\frac{l b}{h r}\right) * 0.2724157\left(\frac{B T U}{l b *^{\circ} \mathrm{F}}\right) *(747-250)\left({ }^{\circ} \mathrm{F}\right) * 0.8 \\
& \mathrm{WHR}_{\text {exhaust }}=2,962,402.281\left(\frac{B T U}{h r}\right)
\end{aligned}
$$

This value was used to determine the mass flow rate of the working fluid to maximize the recovered energy. Since the working fluid entering the exhaust heat 
exchanger undergoes a complete phase change, the energy required to raise the temperature of the working fluid was calculated at the three phases - liquid, vapor and superheated steam.

A.1.3 Energy required to raise the temperature of the working fluid from $250{ }^{\circ} \mathrm{F}$ to $\underline{518^{0} \mathrm{~F}}$

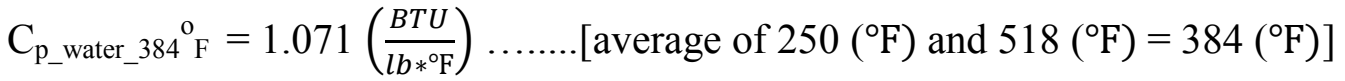

Power $_{250 \_ \text {to_518 }}=\dot{m}_{\text {working_fluid }} * \mathrm{C}_{\mathrm{p}_{-} \text {water_384 }}{ }_{\mathrm{F}}^{\mathrm{O}} * \Delta \mathrm{T}$

Power $_{250 \_ \text {to } 5518}=\dot{m}_{\text {working_fluid }} * 1.071\left(\frac{B T U}{l b *^{\circ} \mathrm{F}}\right) *(518-250)\left({ }^{\circ} \mathrm{F}\right)$

\section{A.1.4 Energy required to evaporate the working fluid at $518^{\circ} \mathrm{F}$ and 800 psia}

Evaporation enthalpy $800 \_$psi $=689.48\left(\frac{B T U}{l b}\right)$

Power $_{\text {evaporation }}=\dot{m}_{\text {working_fluid }} *$ Evaporation enthalpy $800 \_$psi

Power $_{\text {evaporation }}=\dot{m}_{\text {working_fluid }} * 689.48\left(\frac{B T U}{l b}\right)$

\section{A.1.5 Energy required to raise the temperature of the working fluid from $518^{\circ} \mathrm{F}$ to} $747^{\circ} \mathrm{F}$

$\mathrm{C}_{\mathrm{p}_{-} \text {steam } \_659}{ }^{\mathrm{o}} \mathrm{F}=0.6634\left(\frac{B T U}{l b *^{\circ} \mathrm{F}}\right)$

Power $_{518 \_ \text {to_ } 747}=\dot{m}_{\text {working_fluid }} * \mathrm{C}_{\mathrm{p}_{-} \text {steam_659 }}{ }_{\mathrm{F}}^{\mathrm{O}} * \Delta \mathrm{T}$

Power $_{518 \_ \text {to_ } 747}=\dot{m}_{\text {working_fluid }} * 0.6634\left(\frac{B T U}{l b *{ }^{\circ} \mathrm{F}}\right) *(747-518)\left({ }^{\circ} \mathrm{F}\right)$ 


\section{A.1.6 Total energy required to raise the temperature of the working fluid from 250} 年 to $747^{\circ} \mathrm{F}$

Power $_{250 \_t o \_747}=$ Power $_{250 \_t o \_518}+$ Power $_{\text {evaporation }}+$ Power $_{518 \_ \text {to_ } 747}=$ WHR $_{\text {exhaust }}$

Power $_{250 \_ \text {to }} 747=1+2+3$

$2,962,402.281\left(\frac{B T U}{h r}\right)=\dot{m}_{\text {working_fluid }} *(287.028+689.48+151.91)\left(\frac{B T U}{l b}\right)$

Mass flow rate of the working fluid to

maximize recovery of the exhaust gas, $\dot{m}_{\text {working_fluid }}=2625.25\left(\frac{l b}{h r}\right)=0.729\left(\frac{l b}{s}\right)$

\section{Using $\dot{m}_{\text {working_fluid }}$ in the above equations}

$$
\begin{aligned}
& \text { Power } 250 \_ \text {to_518 }=2625.25\left(\frac{l b}{h r}\right) * 1.071\left(\frac{B T U}{l b * *^{\circ} \mathrm{F}}\right) *(518-250)\left({ }^{\circ} \mathrm{F}\right) \\
& =753,520.257\left(\frac{B T U}{h r}\right) \\
& \text { Power }_{\text {evaporation }}=2625.25\left(\frac{l b}{h r}\right) * 689.48\left(\frac{B T U}{l b}\right)=1,810,057.37\left(\frac{B T U}{h r}\right) \\
& \text { Power }_{518 \_ \text {to_ } 747}=2625.25\left(\frac{l b}{h r}\right) * 0.6634\left(\frac{B T U}{l b *{ }^{\circ} \mathrm{F}}\right) *(747-518)\left({ }^{\circ} \mathrm{F}\right) \\
& =398,824.30\left(\frac{B T U}{h r}\right) \\
& \text { Power } 250 \_ \text {to_ } 747=753,520.257\left(\frac{B T U}{h r}\right)+1,810,057.37\left(\frac{B T U}{h r}\right)+398,824.30\left(\frac{B T U}{h r}\right) \\
& \text { Power } 250 \_ \text {to_747 }=2,962,401.932\left(\frac{B T U}{h r}\right) \\
& \mathrm{WHR}_{\text {exhaust }} \approx \text { Power }_{250 \_ \text {to_800 }} \\
& 2,962,402.281\left(\frac{B T U}{h r}\right) \approx 2,962,401.932\left(\frac{B T U}{h r}\right)
\end{aligned}
$$




\section{A.1.7 Maximum WHR from coolant heat exchanger}

The mass flow rate of the working fluid and the maximum temperature of the coolant limit the amount of recoverable energy from the coolant heat exchanger. Exhaust energy analysis must be used to determine the mass flow rate of the working fluid. The maximum temperature of the coolant was set to $250^{\circ} \mathrm{F}$. The incoming working fluid had its temperature set to $212^{\circ} \mathrm{F}$ to reduce the size of the condenser.

\section{A.1.8 Energy required to raise the temperature of the working fluid from $212{ }^{\circ} \mathrm{F}$ to} $\underline{250}{ }^{\circ} \mathrm{F}$

$\mathrm{C}_{\mathrm{p}_{-} \text {water_231 }} \stackrel{\mathrm{o}}{\mathrm{F}}=1.011\left(\frac{B T U}{l b *{ }^{\circ} \mathrm{F}}\right)$

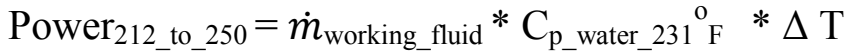

Power $_{212 \_ \text {to } \_250}=2625.25\left(\frac{l b}{h r}\right) * 1.011\left(\frac{B T U}{l b *^{\circ} \mathrm{F}}\right) *(250-212)^{\circ} \mathrm{F}$

$\mathrm{WHR}_{\text {coolant }}=$ Power $212 \_$to_250 $=$Power $_{\text {coolant }}=100,856.854\left(\frac{B T U}{h r}\right)$

\section{A.1.9 Steam chamber bore size}

The steam chamber bore size is greatly affected by the number of steam chambers incorporated in the simulated engine model. The following section shows the different bore sizes that were calculated and a reasonable bore size was chosen.

$$
\begin{aligned}
& \text { Density of steam@747 }{ }^{\circ} \mathrm{F}, 800 \mathrm{psia}, \rho_{747}{ }^{\mathrm{o}} \mathrm{F}_{-} 800 \mathrm{psia}=1.141\left(\frac{l b}{f t^{3}}\right) \\
& \dot{m}_{\text {working_fluid }}=2625.25\left(\frac{l b}{h r}\right)=0.729\left(\frac{l b}{s}\right)
\end{aligned}
$$

Volumetric flow rate of the super-heated steam into the steam chamber, 
$\dot{\forall}_{\text {workingfluid }}=\frac{\dot{m}_{\text {workingfluid }}}{\rho_{800^{\circ} \mathrm{F}_{-} 800 \text { psia }}}=0.638\left(\frac{f t^{3}}{s}\right) * \frac{1,728\left(i n^{3}\right)}{1\left(f t^{3}\right)}=1104.04\left(\frac{i n^{3}}{s}\right)$

\section{A.1.10 Assuming 2 cylinders are equipped with novel WHR system steam chambers}

$$
\begin{aligned}
\dot{\forall}_{\text {workingfluid }} & =\dot{\forall}_{\text {steam_chamber }} * 0.05 \text { (cut off) } * 2 \text { cylinders } \\
\dot{\forall}_{\text {steam_chamber }} & =\frac{\dot{\forall}_{\text {workingfluid }}}{0.05 * 2}=\frac{1104.04}{0.05 * 2}\left(\frac{\mathrm{in}^{3}}{\mathrm{~s}}\right)=11040.420\left(\frac{\mathrm{in}^{3}}{\mathrm{~s}}\right) \\
\dot{\forall}_{\text {steam_chamber }} & =\pi *\left(\frac{\text { bore }_{\text {steamchamber }}}{2}\right)^{2} * \text { stroke }_{\text {enginepiston }} * N \\
\text { bore }_{\text {steamchamber }} & =\sqrt{\frac{\dot{\forall}_{\text {steam_chamber }}}{\pi * \text { stroke }_{\text {enginepiston }} * N}} * 2 \\
& =\sqrt{\frac{11040.420}{\pi * 11.811(\text { in }) * 15\left(\frac{\text { rev }}{\mathrm{s}}\right)}} * 2 \\
& =8.90(\mathrm{in})
\end{aligned}
$$

Volume of the steam chamber, $\mathrm{V}_{\text {steamchamber }}=\pi *\left(\frac{\text { bore }_{\text {steamchamber }}}{2}\right)^{2} *$ stroke enginepiston

$$
\begin{aligned}
& =\pi *\left(\frac{8.90(\mathrm{in})}{2}\right)^{2} * 11.811(\mathrm{in}) \\
& =736.028\left(\mathrm{in}^{3}\right)
\end{aligned}
$$

Volume displacement of the engine piston,

$$
\begin{aligned}
\mathrm{V}_{\text {enginepiston }} & =\pi *\left(\frac{\text { bore }_{\text {enginepiston }}}{2}\right)^{2} * \text { stroke }_{\text {enginepiston }} \\
& =\pi *\left(\frac{10.82}{2}\right)^{2} * 11.811 \\
& =1086\left(\mathrm{in}^{3}\right)
\end{aligned}
$$


Ratio displacement $=\frac{\mathrm{V}_{\text {enginepiston }}}{\mathrm{V}_{\text {steamchamber }}}=\frac{1086\left(\mathrm{in}^{3}\right)}{620.828\left(\mathrm{in}^{3}\right)}=1.475$

\section{A.1.11 Assuming 6 cylinders are equipped with DYNAMAX steam chambers}

$$
\begin{aligned}
& \dot{\forall}_{\text {workingfluid }}=\dot{\forall}_{\text {steam_chamber }} * 0.05 \text { (cut off) } * 6 \text { cylinders } \\
& \dot{\forall}_{\text {steam_chamber }}=\frac{\dot{\forall}_{\text {workingfluid }}}{0.05 * 6}=\frac{1104.04}{0.05 * 6}\left(\frac{\mathrm{in}^{3}}{\mathrm{~s}}\right)=3680.13\left(\frac{\mathrm{in}^{3}}{\mathrm{~s}}\right) \\
& \dot{\forall}_{\text {steam_chamber }}=\pi *\left(\frac{\text { bore }_{\text {steamchamber }}}{2}\right)^{2} * \text { stroke }_{\text {enginepiston }} * N
\end{aligned}
$$

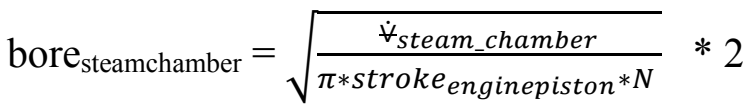

$$
\begin{aligned}
& =\sqrt{\frac{3680.13}{\pi * 11.811(\text { in }) * 15\left(\frac{\text { rev }}{s}\right)}} * 2 \\
& =5.14 \text { (in) }
\end{aligned}
$$

Volume of the steam chamber, $\mathrm{V}_{\text {steamchamber }}=\pi *\left(\frac{\text { bore }_{\text {steamchamber }}}{2}\right)^{2} *$ stroke enginepiston

$$
\begin{aligned}
& \quad=\pi *\left(\frac{5.14(\mathrm{in})}{2}\right)^{2} * 11.811(\mathrm{in}) \\
& =245.342\left(\mathrm{in}^{3}\right)
\end{aligned}
$$

Volume displacement of the engine piston,

$$
\begin{aligned}
\mathrm{V}_{\text {enginepiston }} & =\pi *\left(\frac{\text { bore }_{\text {enginepiston }}}{2}\right)^{2} * \text { stroke }_{\text {enginepiston }} \\
& =\pi *\left(\frac{10.82}{2}\right)^{2} * 11.811 \\
& =1086\left(\mathrm{in}^{3}\right)
\end{aligned}
$$


Ratio displacement $=\frac{\mathrm{V}_{\text {enginepiston }}}{\mathrm{V}_{\text {steamchamber }}}=\frac{1086\left(\mathrm{in}^{3}\right)}{245.342\left(\mathrm{in}^{3}\right)}=4.42$

\section{A.1.12 Theoretical power generation from WHR}

The steam chambers were assumed to be $20 \%$ efficient which is a close approximation by the results acquired from GT-POWER and as per design requirements.

\section{A.1.13 Total amount of recovered waste heat}

$$
\begin{aligned}
\text { Power }_{\text {recovered }} & =\text { Power }_{\text {coolant }}+\text { Power }_{\text {exhaust }} \\
& =100,856.854\left(\frac{B T U}{h r}\right)+2,962,401.932\left(\frac{B T U}{h r}\right) \\
& =3,063,258.786\left(\frac{B T U}{h r}\right)
\end{aligned}
$$

\section{A.1.14 Power generation BEFORE any parasitic losses}

$$
\begin{aligned}
\text { Power }_{\text {generated }} & =\text { Power }_{\text {recovered }} * \eta_{\text {steamengine }} \\
& =3,063,258.786\left(\frac{B T U}{h r}\right) * 0.2 \\
& =612,651.7572\left(\frac{B T U}{h r}\right) \\
& =612,651.7572\left(\frac{B T U}{h r}\right) *\left(\frac{1(h r)}{60(\min )}\right) *\left(\frac{778(h p)}{33,000\left(\frac{B T U}{h r}\right)}\right) \\
& =240.72(\mathrm{hp})
\end{aligned}
$$

\section{A.1.15 Estimated parasitic losses}

The parasitic losses were calculated from the loss to operate the working fluid pump and the loss from the exhaust heat exchanger back pressure. 


\section{A.1.16 Loss from working fluid pump power input}

The pump and the alternator that supplies the necessary electrical power were considered to be $80 \%$ efficient. Also, a 5\% pressure drop was assumed across every component in the system.

Pump efficiency, $\eta_{\text {pump }}=0.8$

Alternator efficiency, $\eta_{\text {alternator }}=0.8$

Incoming pressure to the working fluid pump, pressure $_{\text {in }}=14.7\left(\frac{l b}{i n^{2}}\right)$

Outgoing pressure to the working fluid pump pressure ${ }_{\text {out }}=1,034\left(\frac{l b}{i n^{2}}\right)$

Change in pressure, $\Delta \mathrm{P}=$ pressure $_{\text {out }}-$ pressure $_{\text {in }}$

$$
\begin{aligned}
& =1,034\left(\frac{l b}{i n^{2}}\right)-14.7\left(\frac{l b}{i n^{2}}\right) \\
& =1,019\left(\frac{l b}{i n^{2}}\right) *\left(\frac{144\left(i n^{2}\right)}{1\left(f t^{2}\right)}\right) \\
& =146,779\left(\frac{l b}{i n^{2}}\right)
\end{aligned}
$$

Density of water at $212^{\circ} \mathrm{F}, \rho_{\text {water_212F }}=59.83\left(\frac{l b}{f t^{3}}\right)$

Mass flow rate of the working fluid, $\quad \dot{m}_{\text {working_fluid }}=2625.25\left(\frac{l b}{h r}\right)=0.729\left(\frac{l b}{s}\right)$

Volumetric flow rate of the working fluid as a liquid,

$\dot{\forall}_{\text {workingfluid_liq }}=\left(\frac{\dot{m}_{\text {workingfluid }}}{\rho_{\text {water_212F }}}\right)=\left(\frac{0.729\left(\frac{l b}{s}\right)}{59.83\left(\frac{l b}{f t^{3}}\right)}\right)=0.0121\left(\frac{f t^{3}}{s}\right)$

Power to operate working fluid pump, 


$$
\begin{aligned}
\text { Power }_{\text {loss_pump }}=\left(\frac{\dot{\forall}_{\text {workingfluidliq } * \Delta \mathrm{P}}}{\eta_{\text {pump }} \eta_{\text {alternator }}}\right) & =\left(\frac{0.0121\left(\frac{f t^{3}}{s}\right) * 146,779\left(\frac{l b}{i n^{2}}\right)}{0.8 * 0.8}\right) \\
& =2794.42\left(\frac{f t * l b}{s}\right) *\left(\frac{1(h p)}{550\left(\frac{f t * l b}{s}\right)}\right)=5.08(\mathrm{hp})
\end{aligned}
$$

\section{A.1.17 Loss from exhaust heat exchanger backpressure}

A finned-tube, compact heat exchanger was designed as the exhaust heat exchanger to achieve pressure drops as low as possible. Different configurations were used and the optimum one is chosen as the exhaust heat exchanger. A typical finned-tube, compact heat exchanger configuration is given below.

\section{A.2 DESIGN OF THE HEAT EXCHANGER [4]}

Table 5: Typical configuration of a finned-tube, compact heat exchanger [4]

\begin{tabular}{|l|c|}
\hline \multicolumn{1}{|c|}{ PARAMETERS } & VALUE \\
\hline Tube outside diameter, $\mathrm{D}_{\mathrm{o}}$ & $0.64 \mathrm{in}=0.053 \mathrm{ft}$ \\
\hline Tube inside diameter, $\mathrm{D}_{\mathrm{i}}$ & $0.543 \mathrm{in}=0.045 \mathrm{ft}$ \\
\hline Fin pitch & $902.23 \mathrm{per}$ feet \\
\hline Flow passage hydraulic diameter, $\mathrm{D}_{\mathrm{h}}$ & $0.26 \mathrm{in}=0.021 \mathrm{ft}$ \\
\hline Fin thickness, $\mathrm{t}$ & $0.01 \mathrm{in}=0.0008 \mathrm{ft}$ \\
\hline Free-flow area/frontal area, $\sigma$ & 0.449 \\
\hline Heat transfer area/total volume, $\alpha$ & $6.83 \mathrm{in}^{2} / \mathrm{in}^{3}=82 \mathrm{ft}^{2} / \mathrm{ft}^{3}$ \\
\hline Fin area/total area, $\mathrm{A}_{\mathrm{f}} / \mathrm{A}$ & 0.830 \\
\hline Frontal area, $\mathrm{A}_{\mathrm{f}}$ & $0.20 \mathrm{~m}^{2}=2.152 \mathrm{ft}^{2}$ \\
\hline
\end{tabular}


All the equations used in this design calculation were obtained from [4]

- Effectiveness, $\varepsilon=\frac{q}{q_{\max }}$

where, effectiveness is assumed to be $80 \%, \varepsilon=0.8 \quad$ [Heat exchanger efficiency]

Maximum possible heat transfer rate, $\mathrm{q}_{\max }=\dot{m}_{\text {exhuastgas }} * \mathrm{C}_{\mathrm{p}_{-} \text {exhaustgas }} * \Delta \mathrm{T}$

$$
\begin{aligned}
& =27350.516\left(\frac{l b}{h r}\right) * 0.2724157\left(\frac{B T U}{l b *^{\circ} \mathrm{F}}\right) *(747-250)\left({ }^{\circ} \mathrm{F}\right) \\
& =3,703,002.851\left(\frac{B T U}{h r}\right)
\end{aligned}
$$

Actual heat transfer rate, $\mathrm{q}=q_{\max } x \varepsilon$

$$
\begin{aligned}
& =3,703,002.851\left(\frac{B T U}{h r}\right) \times 0.8 \\
& =2,962,402.281\left(\frac{B T U}{h r}\right)
\end{aligned}
$$

Page 53 of 65 
- $\mathrm{q}_{\max }=\mathrm{C}_{\min }\left(\mathrm{T}_{\mathrm{h}, \mathrm{i}}-\mathrm{T}_{\mathrm{c}, \mathrm{i}}\right)$

where, $\mathrm{C}_{\min }=$ heat capacity rate of cold fluid

$$
\begin{aligned}
& T_{h, i}=\text { Inlet temperature of hot fluid, air }=747^{\circ} \mathrm{F} \\
& T_{c, i}=\text { Inlet temperature of cold fluid, water }=250^{\circ} \mathrm{F}
\end{aligned}
$$

Therefore, heat capacity rate of cold fluid, $C_{\min }=\frac{q_{\max }}{\left(T_{h, i}-T_{c, i}\right)}$

$$
\begin{gathered}
C_{\text {min }}=\frac{3,703,002.851\left(\frac{B T U}{h r}\right)}{(800-250)^{\circ} \mathrm{F}} \\
C_{\text {min }}=7450.70\left(\frac{B T U}{h r^{\circ} \mathrm{F}}\right)
\end{gathered}
$$

- $\mathrm{q}=\mathrm{C}_{\max }\left(\mathrm{T}_{\mathrm{c}, \mathrm{o}}-\mathrm{T}_{\mathrm{c}, \mathrm{i}}\right)$

where, $C_{\max }=$ heat capacity rate of hot fluid

$$
\begin{aligned}
& T_{c, 0}=\text { Outlet temperature of cold fluid, water }=747^{\circ} \mathrm{F} \\
& T_{c, i}=\text { Inlet temperature of cold fluid, water }=250^{\circ} \mathrm{F}
\end{aligned}
$$

Therefore, heat capacity rate of cold fluid, $C_{\max }=\frac{q}{\left(T_{c, o}-T_{c, i}\right)}$

$$
\begin{array}{r}
C_{\max }=\frac{2,962,402.281\left(\frac{B T U}{h r}\right)}{(747-250)^{\circ} \mathrm{F}} \\
C_{\max }=5960.56\left(\frac{B T U}{h r^{\circ} \mathrm{F}}\right) \\
\text { - } \frac{C_{\min }}{C_{\max }}=\frac{7450.70}{5960.56}=1.25 \approx 1
\end{array}
$$




\section{Assumptions:}

- $\mathrm{C}_{\min } / \mathrm{C}_{\max }=1$. This is because $\mathrm{C}_{\min }$ cannot be greater than $\mathrm{C}_{\max }$ and the problem is faced due to the assumption of $250{ }^{\circ} \mathrm{F}$ temperatures of both the incoming working fluid and outgoing exhaust gas. Again, if both the temperatures are equal, the exhaust heat exchanger would be infinitely long. It would be reasonable to assume a different temperature of the outgoing exhaust gas, which is calculated in the following sections.

Assuming negligible fouling effects and

$$
\text { - } \frac{1}{U_{h}}=\frac{1}{h_{c}\left(\frac{A_{c}}{A_{h}}\right)}+A_{h} R_{w}+\frac{1}{\eta_{o, h} h_{h}}
$$

Where, $\mathrm{U}_{\mathrm{h}}=$ overall heat transfer coefficient based on the gas (hot) side surface area

$h_{c} \& h_{h}=$ cold $\&$ hot side convection coefficients respectively

$A_{c} \& A_{h}=$ total gas-side (hot) and water-side (cold) surface areas respectively

$$
\begin{gathered}
R_{w}=\text { Wall conduction resistance } \\
\eta_{o, h}=\text { Overall hot side efficiency }
\end{gathered}
$$

- Assuming negligible fin thickness, $\frac{A_{c}}{A_{h}} \approx \frac{D_{i}}{D_{o}}\left(1-\frac{A_{f, h}}{A_{h}}\right)$

where, $\mathrm{A}_{\mathrm{f}, \mathrm{h}}=$ total gas-side area associated with the fins

$$
\frac{A_{c}}{A_{h}} \approx \frac{0.045 f t}{0.053 f t}(1-0.830) \approx 0.143
$$


- $A_{h} R_{w}=\frac{\ln \left(\frac{D_{o}}{D_{i}}\right)}{2 \pi L k / A_{h}}=\frac{D_{i} \ln \left(\frac{D_{o}}{D_{i}}\right)}{2 k\left(\frac{A_{c}}{A_{h}}\right)}$

$$
\begin{aligned}
& =\frac{0.543(\text { in }) \ln \left(\frac{0.645}{0.543}\right)}{2 \times 1642.42\left(\frac{B T U i n}{h r f t^{2 \circ} \mathrm{F}}\right) \times(0.143)} \\
& =1.98 \times 10^{-4}\left(\frac{h r f t^{2 \circ} \mathrm{F}}{B T U \text { in }}\right)
\end{aligned}
$$

where, the core configuration for the heat exchanger in table 2 is fabricated from aluminum. Therefore, the value of $\mathrm{k}$,

$$
\mathrm{k}=237 \mathrm{~W} / \mathrm{m} * \mathrm{~K}=237 \times 6.93\left(\frac{B T U \text { in }}{h r f t^{20} \mathrm{~F}}\right)=1642.41\left(\frac{B T U \text { in }}{h r f t^{2{ }^{\circ}}}\right)
$$

- Maximum mass velocity, $G=\frac{\dot{\mathrm{m}}}{\sigma * A_{f r}}$

$$
\begin{aligned}
& G=\frac{7.59\left(\frac{l b}{s}\right)}{(0.449) * 2.152 f t^{2}} \\
& G=7.85\left(\frac{l b}{\sec * f t^{2}}\right)
\end{aligned}
$$

- Reynolds number $R e=\frac{G \times D_{h}}{\mu}$

where, $\mu$ for air @ 1atm pressure, $800^{\circ} \mathrm{F}=338.8 \times 10^{-7} \mathrm{~N} . \mathrm{s} / \mathrm{m}^{2}=227.66 \times 10^{-7} \mathrm{lb} /$ $\sec * \mathrm{ft}$

Therefore, Reynolds number $R e=\frac{7.85\left(\frac{l b}{s e c * f t^{2}}\right) \times 0.021 f t}{227.66 \times 10^{-7}\left(\frac{l b}{s e c * f t}\right)}=7262.11$

From the Figure A.1.1, $\mathrm{j}_{\mathrm{h}}=0.007$ [4] 

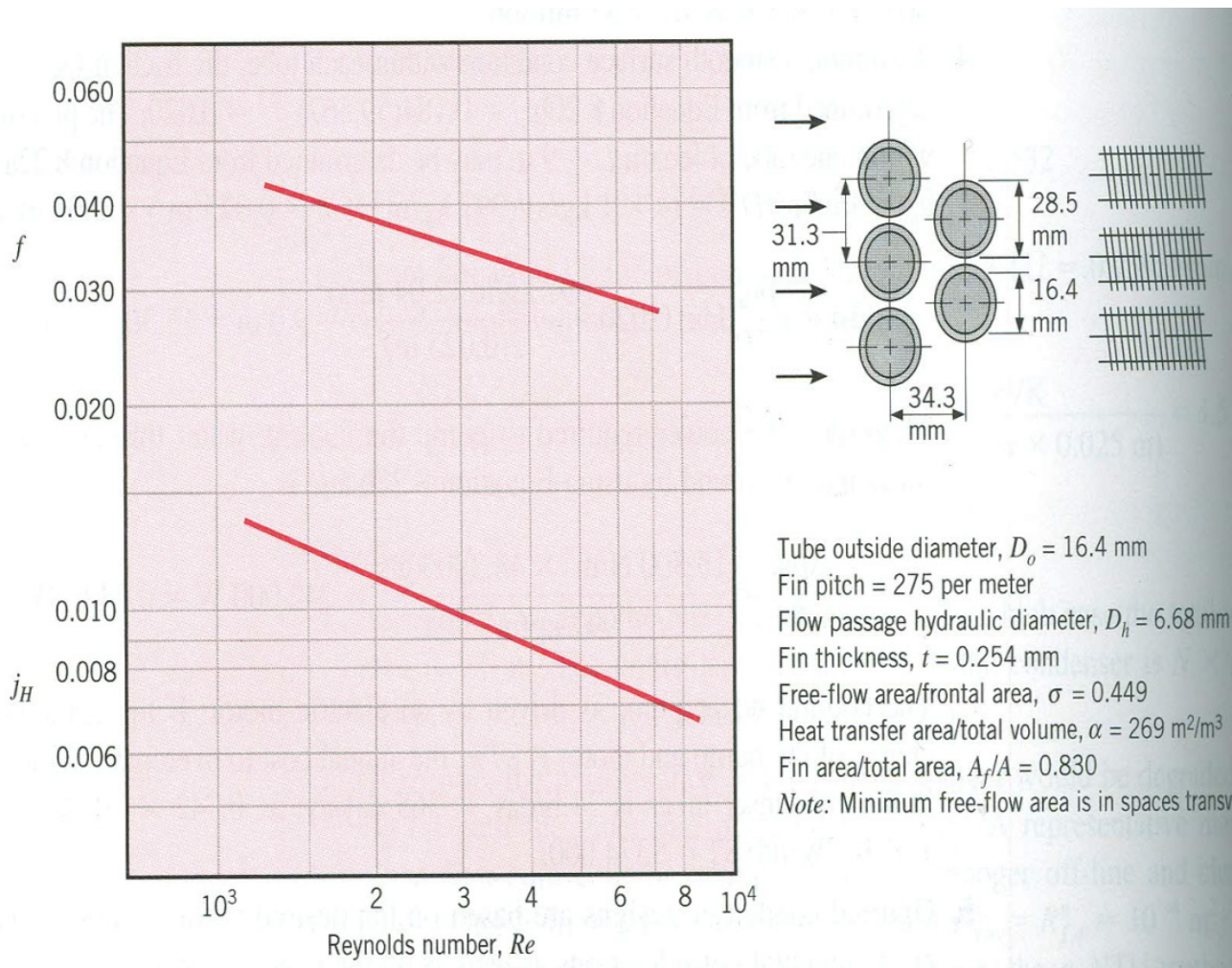

Tube outside diameter, $D_{o}=16.4 \mathrm{~mm}$

Fin pitch $=275$ per meter

Flow passage hydraulic diameter, $D_{h}=6.68 \mathrm{~mm}$

Fin thickness, $t=0.254 \mathrm{~mm}$

Free-flow area/frontal area, $\sigma=0.449$

Heat transfer area/total volume, $\alpha=269 \mathrm{~m}^{2} / \mathrm{m}^{3}$

Fin area/total area, $A_{f} / A=0.830$

Note: Minimum free-flow area is in spaces transverse to fic

Figure A.1.1: Friction factor, $f$ and heat transfer factor, $j_{\mathrm{h}}$ for a circular tube, circular fin heat exchanger [4]

- Hot side convection coefficient, $h_{h}=j_{h} \times \frac{G \times C_{p}}{\operatorname{Pr}^{\wedge} 2 / 3}$

where, $\mathrm{C}_{\mathrm{p}}=0.256\left(\frac{B T U}{l b *^{\circ} \mathrm{F}}\right)$ for air @ 1 1atm and $800^{\circ} \mathrm{F}$

$\operatorname{Pr}=0.695$ for air @ 1 atm and $800^{\circ} \mathrm{F}$

$$
\begin{gathered}
h_{h}=0.007 \times \frac{7.85\left(\frac{l b}{\sec * f t^{2}}\right) \times 0.256\left(\frac{B T U}{l b *{ }^{\circ} \mathrm{F}}\right)}{(0.695)^{\left(\frac{2}{3}\right)}} \\
\mathrm{h}_{\mathrm{h}}=64.54\left(\frac{B T U}{h r f t^{2} \mathrm{~F}}\right)
\end{gathered}
$$

- Cold side convection coefficient, $\mathrm{h}_{\mathrm{c}}=8517.39\left(\frac{B T U \text { in }}{h r f t^{2} \mathrm{~F}}\right)$ 
From the figure A.1.2, the fin efficiency is determined.

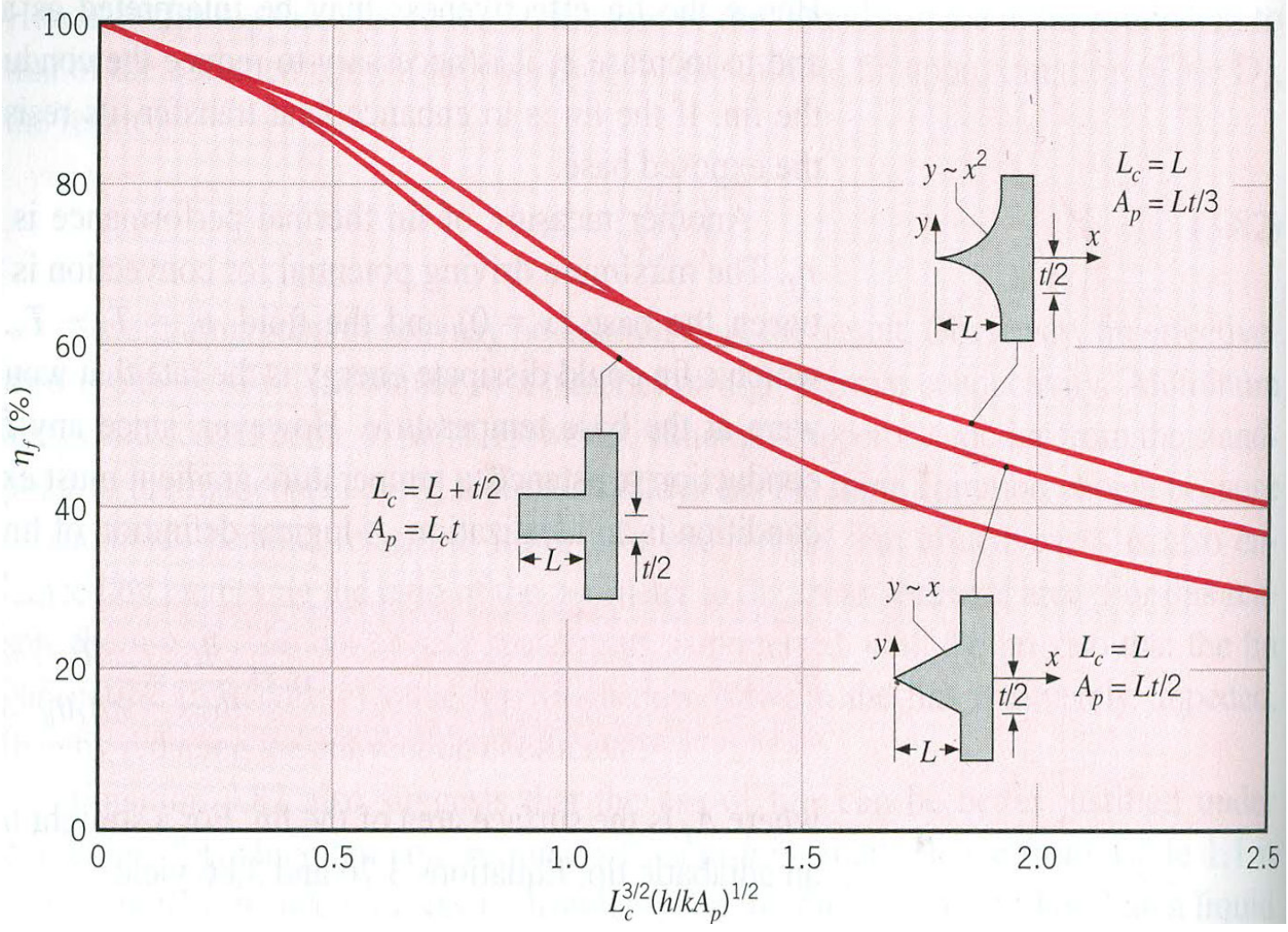

Figure A.1.2: Efficiency of annular fins of rectangular profile [4]

Where, $\mathrm{r}_{2 \mathrm{c}}=0.56 \mathrm{in}, \mathrm{r}_{2 \mathrm{c}} / \mathrm{r}_{1}=1.75, \mathrm{~L}_{\mathrm{c}}=0.24 \mathrm{in}, \mathrm{A}_{\mathrm{p}}=2.43 \times 10^{-3} \mathrm{in}^{2}, \mathrm{~L}_{\mathrm{c}}^{3 / 2}\left(\mathrm{~h}_{\mathrm{h}} /\right.$ $\left.\mathrm{kA}_{\mathrm{p}}\right)^{1 / 2}=0.34$

Using the above values, fin efficiency $\eta_{\mathrm{f}} \approx 89 \%$

Therefore, overall efficiency of hot - side, $\eta_{o, h}=1-\frac{A_{f}}{A}\left(1-\eta_{f}\right)$

- $\eta_{o, h}=1-0.830(1-0.89)=91 \%$ 
Finally, putting all the calculated values in the equation,

$$
\begin{aligned}
& \frac{1}{U_{h}}=\frac{1}{h_{c}\left(\frac{A_{c}}{A_{h}}\right)}+A_{h} R_{w}+\frac{1}{\eta_{o, h} h_{h}} \\
& \frac{1}{U_{h}}=\frac{1}{8517.39\left(\frac{B T U \text { in }}{h r f t^{2 \circ} \mathrm{F}}\right) x(0.143)}+1.98 \times 10^{-4}\left(\frac{h r f t^{2 \circ} \mathrm{F}}{B T U \text { in }}\right)+
\end{aligned}
$$

$\frac{1}{0.91 \times 64.54\left(\frac{B T U i n}{h r f t^{2 \circ} \mathrm{F}}\right)}$

- Overall heat transfer coefficient based on hot - side surface area, $\mathrm{U}_{\mathrm{h}}=55.41$ $\left(\frac{B T U}{h r f t^{2 \circ} \mathrm{F}}\right)$

Number of transferable units (NTU) is an important parameter in designing a heat exchanger. This value can be obtained from either using the figure A.1.3 or using the following equation.

$$
\begin{gathered}
\varepsilon=1-\exp \left[\left(\frac{1}{C_{r}}\right)(N T U)^{0.22}\left\{\exp \left[-C_{r}(N T U)^{0.78}\right]-1\right\}\right] \\
\text { where, } \varepsilon=0.8 \text { and } \mathrm{C}_{\mathrm{r}}=\mathrm{C}_{\min } / \mathrm{C}_{\max }=1 \\
0.8=1-\exp \left[\left(\frac{1}{1}\right)(N T U)^{0.22}\left\{\exp \left[-1(N T U)^{0.78}\right]-1\right\}\right] \\
\mathrm{NTU} \approx 8.1
\end{gathered}
$$




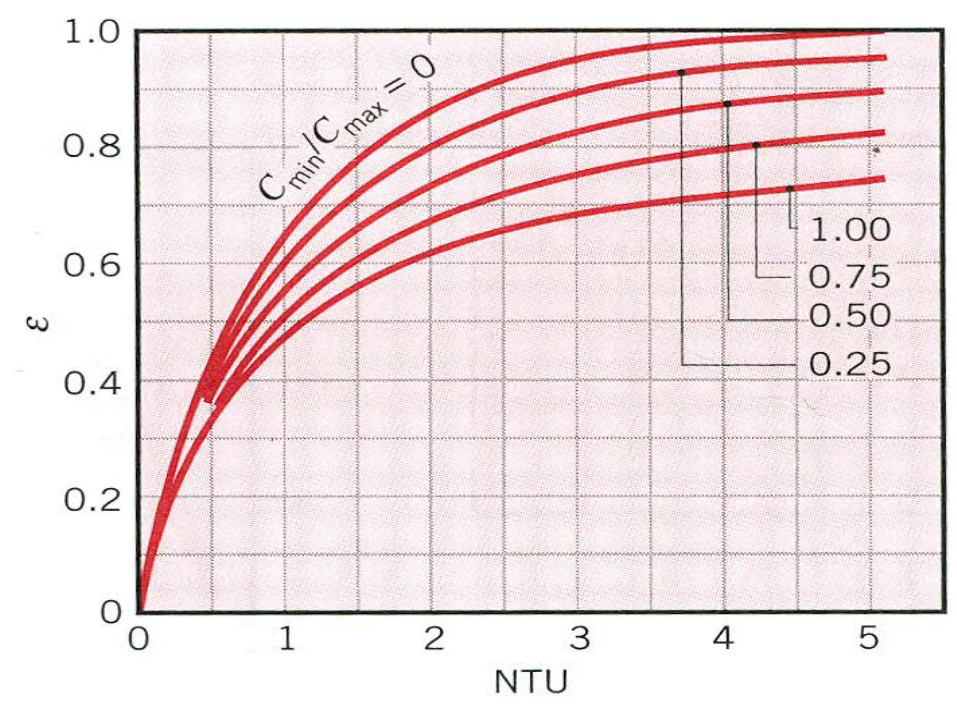

Figure A.1.3: Effectiveness of single-pass, cross-flow heat exchanger with both fluid unmixed

From the figure [A.1.3], on extrapolating the curve for $\mathrm{C}_{\min } / \mathrm{C}_{\max }=1, \mathrm{NTU} \approx 8.1$

The required gas-side heat transfer surface area $\mathrm{A}_{\mathrm{h}}$ is calculated from $N T U=$ $\frac{U_{h} x A_{h}}{C_{\min }}$

- $A_{h}=\frac{N T U \times C_{\min }}{U_{h}}$

$$
\begin{aligned}
& A_{h}=\frac{8.1 \times 7450.70\left(\frac{B T U}{h r^{\circ} \mathrm{F}}\right)}{55.41\left(\frac{B T U}{h r f t^{2 \circ}{ }^{\circ}}\right)} \\
& A_{h}=1089.16 \mathrm{ft}^{2}
\end{aligned}
$$

Required heat exchanger volume, $V=\frac{A_{h}}{\alpha}=\frac{1089.16 f t^{2}}{82\left(\frac{f t^{2}}{f t^{3}}\right)}=13.28 \mathrm{ft}^{3}$ 
- Temperature of the gas leaving the heat exchanger, $T_{h, o}=T_{h, i}-\frac{q}{C_{\min }}$

$$
\begin{aligned}
T_{h, o} & =800^{\circ} \mathrm{F}-\frac{2,962,402.281\left(\frac{B T U}{h r}\right)}{6732.732\left(\frac{B T U}{h r^{\circ} \mathrm{F}}\right)} \\
T_{h, o} & =402.39^{\circ} \mathrm{F}
\end{aligned}
$$

i. Following the assumption of $\left(\mathrm{C}_{\min } / \mathrm{C}_{\max }\right)=1$, the exit temperature of the exhaust gases from the exhaust heat exchanger should be $402.39^{\circ} \mathrm{F}$.

ii. If $\left(\mathrm{C}_{\min } / \mathrm{C}_{\max }\right) \approx 1$ (ie. $\left.0.9-1.2\right)$, then the exit temperature of the exhaust gases from the exhaust heat heat exchanger can be in the range of $250^{\circ} \mathrm{F}-402.39^{\circ} \mathrm{F}$.

iii. Using $250^{\circ} \mathrm{F}$ as the exit temperature of the exhaust gases, the pressure drop calculated below would be 0.511 psi.

iv. For a more reasonable set of calculations, the temperature of $402.39^{\circ} \mathrm{F}$ is used to calculate the pressure drop.

From the figure [17], friction factor $=0.028$

- $\left(\frac{A}{A_{f f}}\right)=\left(\frac{\alpha V}{\sigma A_{f r}}\right)=\left(\frac{82\left(\frac{f t^{2}}{f t^{3}}\right) \times 13.28 f t^{3}}{0.449 \times 2.152 f t^{2}}\right)=1126.99$

- Pressure drop, $\Delta P=\frac{G^{2} \mathrm{v}_{i}}{2}\left[\left(1+\sigma^{2}\right)\left(\frac{\mathrm{v}_{o}}{\mathrm{v}_{i}}-1\right)+f\left(\frac{A}{A_{f f}}\right)\left(\frac{\mathrm{v}_{m}}{\mathrm{v}_{i}}\right)\right]$

Inlet specific volume of air, $\mathrm{v}_{i}\left(800^{\circ} \mathrm{F}\right)=32.19\left(\mathrm{ft}^{3} / \mathrm{lb}\right)$

Outlet specific volume of air, $\mathrm{v}_{0}\left(402.39^{\circ} \mathrm{F}\right)=15.20\left(\mathrm{ft}^{3} / \mathrm{lb}\right)$

Average of inlet and outlet specific volume, $\mathrm{v}_{m}\left(579.995^{\circ} \mathrm{F}\right)=23.69\left(\mathrm{ft}^{3} / \mathrm{lb}\right)$ 


$$
\begin{aligned}
\Delta P=\frac{\left(7.85 \frac{l b}{\sec * f t^{2}}\right)^{2} \times 32.19(\mathrm{ft} 3 / \mathrm{lb})}{2}\left[(1+0.202)\left(\frac{15.20}{32.19}-1\right)\right. \\
\left.\quad+0.028(1126.99)\left(\frac{23.69}{32.19}\right)\right] \\
=2882.97 \frac{l b}{\sec ^{2} * f t} \\
=4296\left(\mathrm{~N} / \mathrm{m}^{2}\right)
\end{aligned}
$$

- $\Delta P=0.623 \mathrm{psi}$

The exhaust heat exchanger calculations were limited to the specifications provided in table 1 and the pressure drop calculated is $0.623 \mathrm{psi}$ which is reasonably good. Since the size of the Waukesha 16V275GL+ engine is very large (9054 mm x 2565 $\mathrm{mm}$ ) compared to the size of the exhaust heat exchanger $\left(13.28 \mathrm{ft}^{3}\right)$, parameters in table 2 can be adjusted to reach the lowest possible backpressure. To attain a zero psi backpressure, the heat exchanger must be infinitely long. The trend of the backpressures versus volume of the exhaust heat exchanger is predicted and plotted in the figure below. 


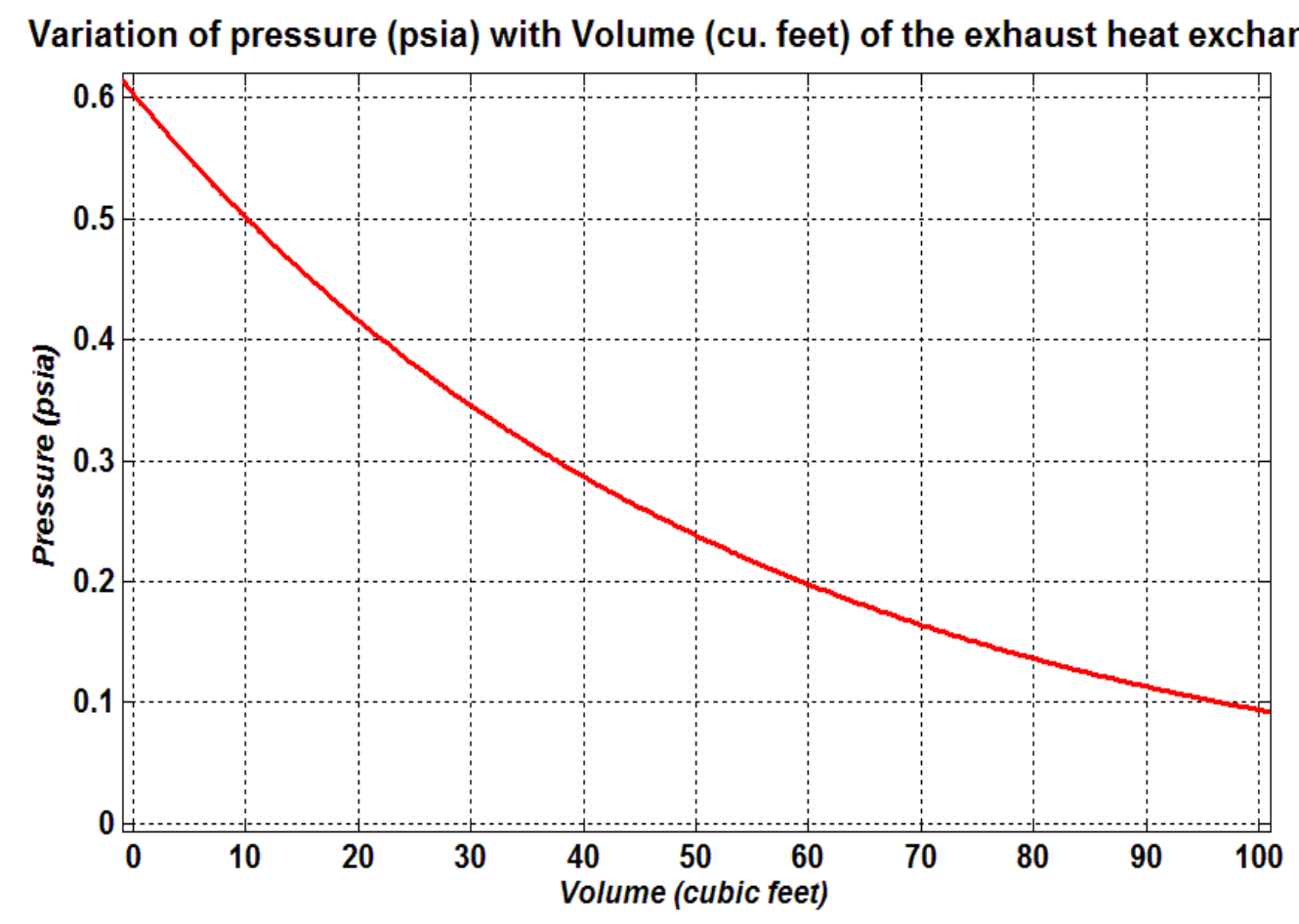

Figure A.1.4: Predicted trend of pressure (psia) vs. volume (cu.ft) of the exhaust heat exchanger

After the estimation of required backpressure for the exhaust heat exchanger, losses due to it are calculated below.

$$
\begin{array}{ll}
\text { Pressure }_{\text {exhaust } \mathrm{HE}} & =0.623\left(\frac{l b}{i n^{2}}\right) *\left(\frac{144\left(i n^{2}\right)}{1\left(f t^{2}\right)}\right)=89.712\left(\frac{l b}{f t^{2}}\right) \\
\dot{m}_{\text {exhaustgas }} & =\frac{27350.516\left(\frac{l b}{h r}\right)}{\frac{3600(s)}{1(h r)}}=7.597\left(\frac{l b}{s}\right) \\
\rho_{\text {exhaust gas }} & =0.033\left(\frac{l b}{f t^{3}}\right)
\end{array}
$$

Volumetric flow rate of the exhaust gas,

$$
\dot{\forall}_{\text {exh gas }}=\left(\frac{\dot{\mathrm{m}}_{\text {exhaustgas }}}{\rho_{\text {exhaustgas }}}\right)=\left(\frac{7.597}{0.033}\right)\left(\frac{f t^{3}}{s}\right)=230.21\left(\frac{f t^{3}}{s}\right)
$$


Power $_{\text {loss_exhaust }}=\forall_{\text {exh gas }} *$ Pressure $_{\text {exhaust } \mathrm{HE}}$

$$
\begin{aligned}
& =230.21\left(\frac{f t^{3}}{s}\right) * 89.712\left(\frac{l b}{f t^{2}}\right) \\
& =20652.59\left(\frac{f t * l b}{s}\right) *\left(\frac{1(h p)}{550\left(\frac{f t * l b}{s}\right)}\right)=37.55(\mathrm{hp})
\end{aligned}
$$

Total parasitic losses, $\mathrm{P}_{\text {loss_total }}=37.55(\mathrm{hp})+5.08(\mathrm{hp})=42.63 \mathrm{hp}$

\section{A.3 Theoretical net efficiency}

\section{A.3.1 Power input from fuel}

Power $_{\text {brake }}=4350(\mathrm{hp})$

$\eta_{\text {brake_fuel_conversion }}=0.3691$

Power $_{\text {fuel }}=\left(\frac{\text { Power }_{\text {brake }}}{\eta_{\text {brake_fuel_conversion }}}\right)=11785.424(\mathrm{hp})$

\section{A.3.2 New efficiency of the system}

$$
\begin{aligned}
\eta_{\mathrm{ci} / \text { steam }} & =\left(\frac{\text { Total power out }}{\text { Total energy rate in }}\right) * 100 \% \\
& =\left(\frac{\text { Power }_{\text {brake }}+\text { Power }_{\text {gen }}-\text { Power }_{\text {total_loss }}}{\text { Total energyrate in }}\right) * 100 \% \\
& =\left(\frac{4350(\mathrm{hp})+240.72(\mathrm{hp})-42.63}{11785.424}\right) * 100 \% \\
& =38.58 \%
\end{aligned}
$$




\section{A.3.3 Increase in net efficiency}

$$
\begin{aligned}
\eta_{\text {increase }} & =\frac{\eta_{\text {ci } / \text { steam }}-\eta_{\text {brake_fuel_conversion }}}{\eta_{\text {brake_fuel_conversion }}} \\
& =\frac{0.3858-0.3691}{0.3691} \\
& =4.53 \%
\end{aligned}
$$

Note: The backpressure can be reduced to lower than 0.623 psia depending on the required size of the heat exchanger. 